\title{
Hydrogels Synthesized by Electron Beam Irradiation for Heavy Metal Adsorption
}

\author{
Elena Manaila ${ }^{1}$, Gabriela Craciun ${ }^{1, *}$, Daniel Ighigeanu ${ }^{1}$, Catalina Cimpeanu ${ }^{2}$, Catalina Barna ${ }^{2}$ \\ and Viorel Fugaru ${ }^{2}$ \\ 1 National Institute for Laser, Plasma and Radiation Physics, Electron Accelerators Laboratory, \\ \#409 Atomistilor St., Magurele 077125, Romania; elena.manaila@inflpr.ro (E.M.); \\ daniel.ighigeanu@inflpr.ro (D.I.) \\ 2 Horia Hulubei National Institute for Physics and Nuclear Engineering, 30 Reactorului St., Magurele 077125, \\ Romania; catalinac@nipne.ro (C.C.); catalina.barna@nipne.ro (C.B.); vfugaru@nipne.ro (V.F.) \\ * Correspondence: gabriela.craciun@inflpr.ro; Tel.: +40-(0)2-1457-4346
}

Academic Editor: Biqiong Chen

Received: 11 April 2017; Accepted: 12 May 2017; Published: 18 May 2017

\begin{abstract}
Poly(acrylamide co-acrylic acid) hydrogels were prepared by free-radical copolymerization of acrylamide and acrylic acid in aqueous solutions using electron beam irradiation in the dose range of $2.5 \mathrm{kGy}$ to $6 \mathrm{kGy}$ in atmospheric conditions and at room temperature. The influence of the absorbed dose, the amount of cross-linker (trimethylolpropane trimethacrylate) and initiator (potassium persulfate) on the swelling properties and the diffusion coefficient and network parameters of hydrogels were investigated. The structure and morphology of hydrogels were characterized by Fourier Transform Infrared Spectroscopy (FTIR) and Scanning Electron Microscopy (SEM). The use of the obtained hydrogels by the removal of $\mathrm{Cu}^{2+}$ and $\mathrm{Cr}^{6+}$ from aqueous solutions was investigated at room temperature. During the adsorption of metal ions on hydrogels, the residual metal ion concentration in the solution was measured by an atomic absorption spectrophotometer (AAS). It has been established that the use of a relatively small amount of trimethylolpropane trimethacrylate for hydrogel preparation has led to the increasing of swelling up to $8500 \%$.
\end{abstract}

Keywords: hydrogels; electron beam irradiation; cross-linking; trimethylolpropane trimethacrylate

\section{Introduction}

Heavy metal ions are harmful and toxic to human beings and the environment. Therefore, they must be removed from wastewater and drinking water. The main threats to human health from heavy metals $(\mathrm{HM})$ are associated with exposure to cadmium $(\mathrm{Cd})$, lead $(\mathrm{Pb})$, mercury $(\mathrm{Hg})$ and arsenic (As) (arsenic is a metalloid, but is usually classified as a HM), but additionally, there are other elements known as HM: antimony $(\mathrm{Sb})$, bismuth $(\mathrm{Bi})$, cerium $(\mathrm{Ce})$, chromium $(\mathrm{Cr})$, cobalt $(\mathrm{Co})$, copper $(\mathrm{Cu})$, gallium $(\mathrm{Ga})$, gold $(\mathrm{Au})$, iron $(\mathrm{Fe})$, manganese $(\mathrm{Mn})$, molybdenum $(\mathrm{Mo})$, nickel $(\mathrm{Ni})$, platinum $(\mathrm{Pt})$, silver $(\mathrm{Ag})$, tellurium $(\mathrm{Te})$, thallium $(\mathrm{Tl})$, tin $(\mathrm{Sn})$, uranium $(\mathrm{U})$, vanadium $(\mathrm{V})$ and zinc (Zn) [1]. Some heavy metals (e.g., $\mathrm{Fe}, \mathrm{Zn}, \mathrm{Cu}, \mathrm{Co}, \mathrm{Mn}$ and $\mathrm{Mo}$ ) in small quantities are nutritionally essential for the maintenance of human metabolism [2]. However, heavy metals are also very toxic and non-biodegradable; hence, they can readily be accumulated in an ecological system, induce irreversible pollution, or cause adverse health effects in the human body [3]. Because they are non-biodegradable and can accumulate in the food chain, heavy metal ions from industrial effluents seriously threaten the environment and public health, even at very low concentrations [4-6]. Increasing effort has been concentrated on developing various methods that can effectively remove heavy metal ions from aqueous environments [7]. Some widespread methods for removing heavy metals include chemical coagulation and precipitation $[8,9]$, membrane filtration $[10,11]$, ion exchange $[12,13]$ and 
electrochemical technologies [14]. They have been developed for the early detection and removal of toxic heavy metals from environments, but limited success has been achieved to date due to their low efficiency and the further generation of toxic sludge or other waste products. Additionally, these methods require expensive equipment and involve time-consuming and laborious procedures [15]. Alternatively, adsorption offers many potential advantages for the removal of toxic heavy metals over other methods, thanks to its flexibility in design and operation, high-quality treated effluent, reversible nature for multiple uses and many commercially available adsorbent materials, such as activated carbon [16,17], zeolite [18], clay [19,20], lignin, chitosan and other polymer adsorbents [7,21]. Compared to the conventional adsorbent materials above, hydrogel-based adsorbents have attracted special attention due to their high potential for the effective removal of heavy metals [15,22]. Hydrogels usually have physically well-defined three-dimensional porous structures and chemically responsive functional groups, which enable one to readily capture metal ions from wastewater and to release and clear them upon changes in aqueous solution conditions [15,23]. The hydrophilic character of hydrogel adsorbents enables them to form a flexible network of polymer chains, which allows metal ions to quickly penetrate into the water network and form stable complexes with functional groups [15,24]. Various techniques are used for hydrogel preparation [25], such as physical and chemical cross-linking [26,27], grafting polymerization [28] and radiation cross-linking [29,30]. The radiation technique is more preferable than the chemical one, because of the advantage offered by the gentle control of cross-linking level by variation of the absorbed dose. In some studies, hydrogels have been obtained by simultaneous free radical copolymerization and cross-linking in the presence of polyfunctional monomers with or without the use of radiation techniques [31-34].

This study carries on from previously performed research [35]. The poly(acrylamide co-acrylic acid) hydrogels were prepared by free-radical copolymerization of acrylamide and acrylic acid in aqueous solutions using electron beam irradiation in the dose range of $2.5 \mathrm{kGy}$ to $6 \mathrm{kGy}$ in atmospheric conditions and at room temperature. The influence of the absorbed dose, the amount of cross-linker (trimethylolpropane trimethacrylate) and the initiator (potassium persulfate) on the swelling properties, the diffusion coefficient and the network parameters of hydrogels was investigated. The structure and morphology of hydrogels were characterized by Fourier Transform Infrared Spectroscopy (FTIR) and Scanning Electron Microscopy (SEM). The use of the obtained hydrogels by the removal of $\mathrm{Cu}^{2+}$ and $\mathrm{Cr}^{6+}$ from aqueous solutions was investigated at room temperature. During the adsorption of metal ions on hydrogels, the residual metal ion concentration in the solution was measured by an atomic absorption spectrophotometer (AAS).

\section{Experimental}

\subsection{Materials}

The materials used for experiments are shown in Table 1. Acrylamide (AMD), acrylic acid (AA), potassium persulfate (PP, as initiator) and trimethylolpropane trimethacrylate (TMPT, as cross-linker), were purchased from Sigma Aldrich (Redox Group Company, Buchares, Romania) and were used without further purification.

The metal ions $\mathrm{Cu}^{2+}$ and $\mathrm{Cr}^{6+}$ were provided as $\mathrm{CuSO}_{4}$ and $\mathrm{K}_{2} \mathrm{Cr}_{2} \mathrm{O}_{7}$ by Sigma Aldrich (Redox Group Company, Bucharest, Romania). These reagents were of analytical grade and prepared with double-distilled water. 
Table 1. The materials used for hydrogel preparation.

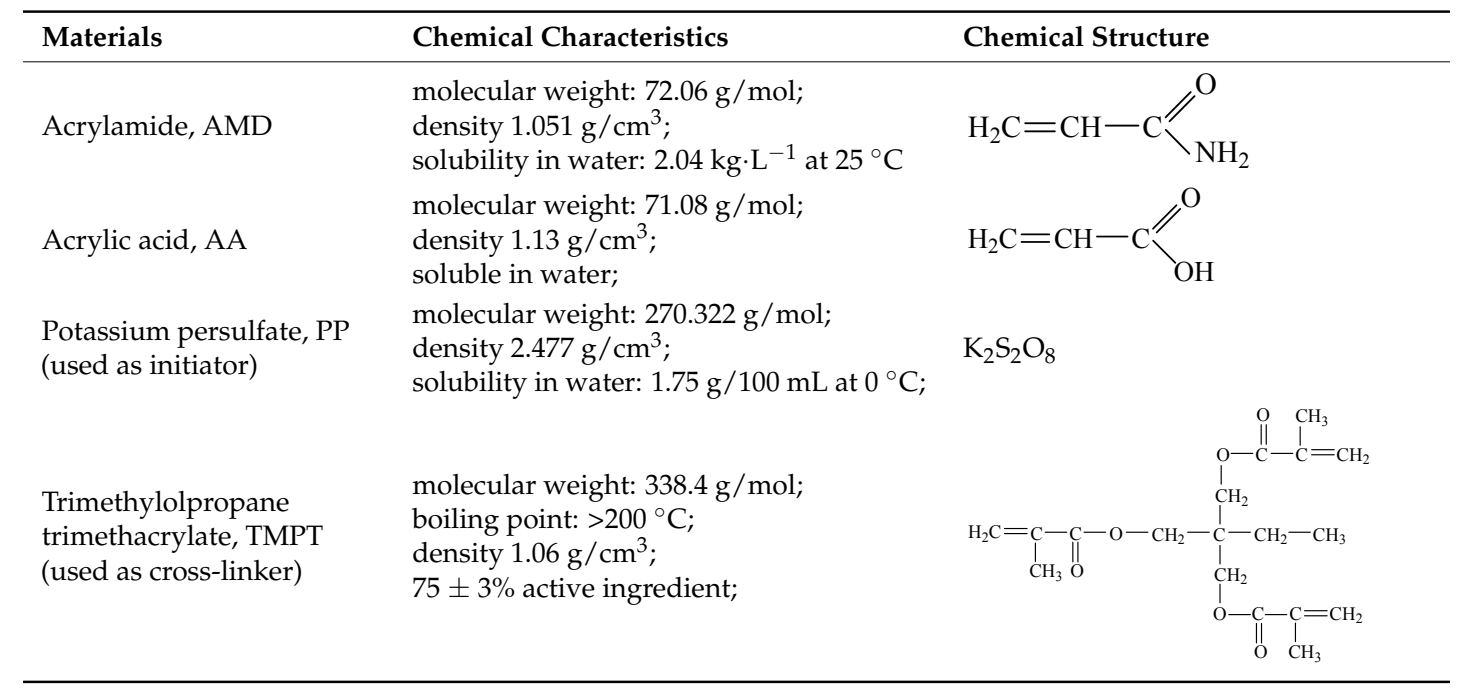

\subsection{Experimental Installation and Sample Preparation}

The hydrogels were obtained by irradiation using an electron beam accelerator called ALID-7, in atmospheric conditions and at a room temperature of $25^{\circ} \mathrm{C}$. ALID-7 was built in the Electron Accelerators Laboratory from the National Institute for Lasers, Plasma and Radiation Physics, Bucharest, Romania. ALID-7 is a linear electron accelerator of travelling-wave type, operating at a wavelength of $10 \mathrm{~cm}$. The accelerating structure is a disk-loaded tube operating in the $\pi / 2$ mode. The optimum values of the electron beam (EB) parameters, namely peak current $\mathrm{I}_{\mathrm{EB}}$ and $\mathrm{EB}$ energy $\mathrm{E}_{\mathrm{EB}}$, to produce maximum output power $\mathrm{P}_{\mathrm{EB}}$ for a fixed pulse duration $\tau_{\mathrm{EB}}$ and repetition frequency $\mathrm{f}_{\mathrm{EB}}$ are as follows: $\mathrm{E}_{\mathrm{EB}}=5.5 \mathrm{MeV}, \mathrm{I}_{\mathrm{EB}}=130 \mathrm{~mA}, \mathrm{P}_{\mathrm{EB}}=670 \mathrm{~W}\left(\mathrm{f}_{\mathrm{EB}}=250 \mathrm{~Hz}, \tau_{\mathrm{EB}}=3.75 \mu \mathrm{s}\right)$.

The EB effects are related to the absorbed dose $(\mathrm{D})$ and absorbed dose rate $\left(\mathrm{D}^{*}\right)$. The absorbed dose is the major parameter in the electron beam irradiation [36]. The performances of polymerization and copolymerization processes are provided by the strict control of this parameter [36]. In our experiments the electron beam dose rate was fixed at $2 \mathrm{kGy} / \mathrm{min}$ in order to accumulate doses between $2.5 \mathrm{kGy}$ and $6 \mathrm{kGy}$. The absorbed dose was determined using the graphite calorimeter and conventional Fricke dosimeter. An important step was the establishment of the electron beam penetration depth in the sample, in order to ensure equal doses at the entry and exit of the irradiated sample. The thickness requirements of the material were calculated from the following relationship [37]:

$$
E=2.6 \times t \times \rho+0.3
$$

where $E[\mathrm{MeV}]$ is the beam energy, in our case $5.5 \mathrm{MeV} ; t[\mathrm{~cm}]$ is the thickness; and $\rho\left[\mathrm{g} \cdot \mathrm{cm}^{-3}\right]$ is the sample density, in our case $1 \mathrm{~g} \cdot \mathrm{cm}^{-3}$.

The thickness of the irradiated samples was set at $20 \mathrm{~mm}$. For irradiation, two types of aqueous solutions were prepared (Table 2). The solutions were placed in polyvinylchloride (PVC) containers with a $3 \mathrm{~cm}$ diameter and irradiated using electron beam irradiation in the dose range of $2.5 \mathrm{kGy}$ to $6 \mathrm{kGy}$ in atmospheric conditions and at a room temperature of $25^{\circ} \mathrm{C}$.

After irradiation, the obtained hydrogels were cut into pieces of 3-4 $\mathrm{mm}$ in length, dried in the air for three days and then in a laboratory oven at $50^{\circ} \mathrm{C}$ for $12 \mathrm{~h}$ to reach a constant weight and then stored in desiccators. The dried hydrogels were used to determine the parameters of swelling, diffusion and network. 
Table 2. Hydrogel synthesis details.

\begin{tabular}{|c|c|c|c|c|c|}
\hline \multirow{2}{*}{ Samples Codes } & \multicolumn{4}{|c|}{ Amount of Chemicals (mol/L) } & \multirow{2}{*}{ Irradiation Dose (kGy) } \\
\hline & AMD & AA & PP & TMPT & \\
\hline $\mathrm{Hyd}_{1.1}$ & \multirow{6}{*}{5} & \multirow{6}{*}{0.5} & \multirow{6}{*}{$3.70 \times 10^{-3}$} & \multirow{6}{*}{$2.95 \times 10^{-3}$} & 2.5 \\
\hline Hyd $_{1.2}$ & & & & & 3.4 \\
\hline Hyd $_{1.3}$ & & & & & 4.2 \\
\hline Hyd $_{1.4}$ & & & & & 4.6 \\
\hline Hyd $_{1.5}$ & & & & & 5.3 \\
\hline Hyd $_{1.6}$ & & & & & 6.0 \\
\hline $\mathrm{Hyd}_{2.1}$ & \multirow{6}{*}{5} & \multirow{6}{*}{0.5} & \multirow{6}{*}{$7.40 \times 10^{-3}$} & \multirow{6}{*}{$5.90 \times 10^{-3}$} & 2.5 \\
\hline $\mathrm{Hyd}_{2.2}$ & & & & & 3.4 \\
\hline $\mathrm{Hyd}_{2.3}$ & & & & & 4.2 \\
\hline $\mathrm{Hyd}_{2.4}$ & & & & & 4.6 \\
\hline $\mathrm{Hyd}_{2.5}$ & & & & & 5.3 \\
\hline $\mathrm{Hyd}_{2.6}$ & & & & & 6.0 \\
\hline
\end{tabular}

\subsection{Measurements}

Before making any measurements, the hydrogels were appraised visually as ductile materials. During the tests, all the samples used remained intact; they did not break or shatter.

Experiments of swelling and network studies: The swelling of dried hydrogels was carried out by immersion in double-distilled water at $25 \pm 0.1^{\circ} \mathrm{C}$ in a water bath. After wiping with filter paper at $24,48,72$ and $96 \mathrm{~h}$, the amount of absorbed water was determined by weighing the samples with an electronic balance (HR 200, $0.1 \mathrm{mg}$ resolution). The experiments were carried out in triplicate and the data were reported as average values.

Metal ion uptake studies: Uptake experiments of metal ions at different $\mathrm{pHs}$ were achieved using the hydrogels as sorbents. Sorption was carried out by immersion of $0.5 \mathrm{~g}$ of each dried hydrogel in $100 \mathrm{~mL}$ aqueous media containing varying concentrations of ions of $\mathrm{Cu}^{2+}$ and $\mathrm{Cr}^{6+}$, for $72 \mathrm{~h}$ at room temperature $\left(25 \pm 0.1{ }^{\circ} \mathrm{C}\right)$. The $\mathrm{pH}$ was adjusted using $0.1 \mathrm{M} \mathrm{NaOH}$ and $0.1 \mathrm{M} \mathrm{HCl}$. For samples that showed maximum uptake, the residual concentration of metal ions was measured using a GBC Avanta $\Sigma$ atomic absorption spectrometer (AAS) (GBC Scientific Equipment Pty Ltd/Victoria, Australia). Chromium and copper determination methods had the following parameters: $\mathrm{Cr}-425.4 \mathrm{~nm}$ wavelength, $0.17 \mu \mathrm{g} / \mathrm{mL}$ sensitivity, $6 \mathrm{~mA}$ lamp current, air-acetylene flame and $\mathrm{Cu}-324.7 \mathrm{~nm}$ wavelength, $0.025 \mu \mathrm{g} / \mathrm{mL}$ sensitivity, $3 \mathrm{~mA}$ lamp current, air-acetylene flame.

FTIR analysis: In order to obtain spectral information regarding the chemical structure of hydrogels, a FTIR spectrophotometer-Bruker Tensor 27 (Bruker, Bremen, Germany) was used by the ATR measurement method. Samples' spectra are the average of 30 scans realized in absorption, in the range of $4000-600 \mathrm{~cm}^{-1}$, with a resolution of $4 \mathrm{~cm}^{-1}$.

Scanning Electron Microscopy (SEM): The morphology of the lyophilized hydrogels was determined using a scanning electron microscope (FEI/Phillips, Hillsboro, OR, USA). Small pieces of swelled gels were freeze-dried in order to avoid the collapse of the porous structure. Freeze-drying was carried out in a vacuum at $-80^{\circ} \mathrm{C}$ for $40 \mathrm{~h}$ using the Christ Alfa 2-4 (Martin Christ, Osterode am Hartz, Germany) lyophilizer. For scanning, the lyophilized samples have been cut in order to expose the inner surface. Samples were placed on an aluminum mount, sputtered with gold palladium and then scanned at an accelerating voltage up to $30 \mathrm{kV}$. 


\section{Results and Discussion}

\subsection{Swelling and Diffusion Experiments}

\subsubsection{The Measurement of Gel Content}

The hydrogel content of a given material is estimated by measuring its insoluble part in dried samples after immersion in water. To perform measurements, dried samples of $0.05 \mathrm{~g}$ were immersed in double-distilled water in order to swell for $72 \mathrm{~h}$ [38]. After filtration, the extracted gel was dewatered with a non-solvent ethanol, dried out in the air and then in a laboratory oven for $5 \mathrm{~h}$ at $70{ }^{\circ} \mathrm{C}$ and finally reweighed. The gel content was calculated as follows:

$$
\operatorname{Gel}(\%)=\frac{W_{1}}{W_{0}} \times 100
$$

where $W_{0}$ is the initial weight of the dried sample and $W_{1}$ is the weight of sample after extraction from the water and drying.

In Figure 1 is presented the effect of the electron beam absorbed dose, cross-linking agent (TMPT) and initiator (PP) amount on the hydrogels' gel content. For a low dose of $2.5 \mathrm{kGy}$, the gel content is over $80 \%$ for both hydrogel types, $\mathrm{Hyd}_{1}$ and $\mathrm{Hyd}_{2}$, which differ by the amount of TMPT and PP. For both hydrogel types, the gel content increases with an increase in the absorbed dose. About $90 \%$ gel content is attained at doses higher than $5.3 \mathrm{kGy}$. Also, the gel content depends on the concentration of initiator and cross-linker. It has been observed that, when increasing the TMPT and PP amount, the gel content increases. If the concentration of TMPT (cross-linking agent) increases, there will be more cross-linking so that the gel content increases.

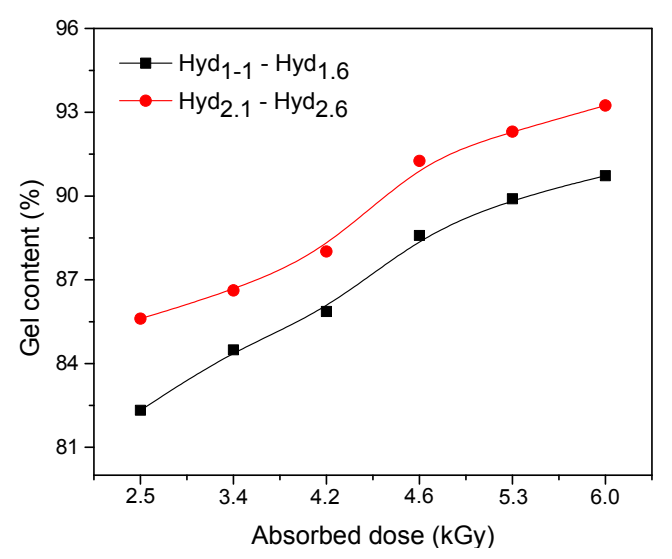

Figure 1. The effect of the absorbed dose on the gel fraction of hydrogels.

\subsubsection{Degree of Swelling}

Furthermore, dynamic swelling experiments have been performed on the cross-linked AMD/AA/TMPT hydrogels in double-distilled water, at room temperature $\left(25 \pm 0.1{ }^{\circ} \mathrm{C}\right)$, in order to determine the maximum water uptake. The mass increase was pursued as a function of time. Also, all the samples were weighed at 24, 48 and $72 \mathrm{~h}$. This determination was absolutely necessary in order to establish the time of immersion of hydrogels in aqueous solutions with heavy metals.

The water uptake, expressed in percentage, was calculated via the following equation [34,39]:

$$
S(\%)=\frac{M_{t}-M_{0}}{M_{0}} \times 100
$$

where $M_{t}$ is the mass of the swollen gel at time $t$ and $M_{0}$ is the initial mass of the dried gel (at time $t=0)$. 
The water uptake in hydrogels at 24,48 and $72 \mathrm{~h}$, as a function of the absorbed dose and the amount of cross-linker and initiator, is shown in Figure 2. The hydrogels' swelling isotherms, as a function of absorbed dose and amount of cross-linker, are shown in Figure 3.
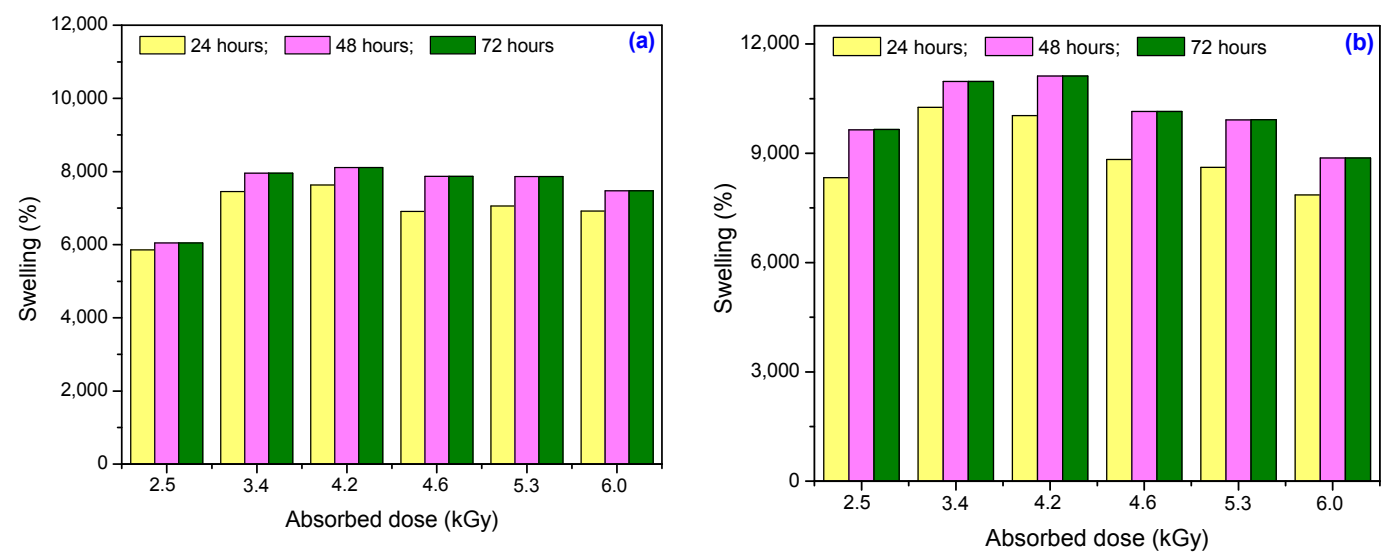

Figure 2. The effect of the absorbed dose on the hydrogels' water uptake at 24,48 and $72 \mathrm{~h}:(\mathbf{a}) 3.70 \times 10^{-3} \mathrm{~mol} / \mathrm{L} \mathrm{PP}$ and $2.95 \times 10^{-3} \mathrm{~mol} / \mathrm{L} \mathrm{TMPT}$; (b) $7.40 \times 10^{-3} \mathrm{~mol} / \mathrm{L} \mathrm{PP}$ and $5.90 \times 10^{-3} \mathrm{~mol} / \mathrm{L} \mathrm{TMPT}$.
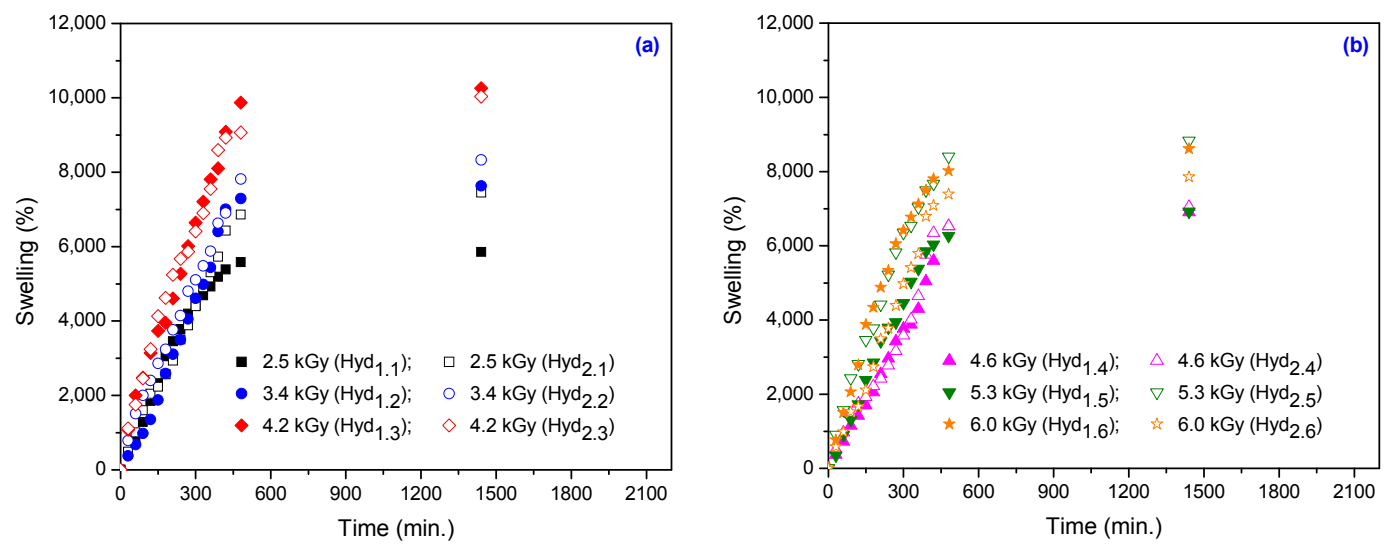

Figure 3. The effect of the amount of TMPT and PP on the swelling for hydrogels obtained at: (a) $2.5 \mathrm{kGy}, 3.4 \mathrm{kGy}$ and $4.2 \mathrm{kGy}$; (b) $4.6 \mathrm{kGy}, 5.3 \mathrm{kGy}$ and $6.0 \mathrm{kGy}$.

As can be seen in Figure 2, the water uptake increases with the increase of the TMPT and PP amount at the same absorbed dose. Water uptake increases with the increase of the absorbed dose up to a maximum of $4.2 \mathrm{kGy}$ and, after that, decreases with an increase in absorbed dose because the degree of cross-linking increases and the entrance of water is restricted. Also, the hydrogels with a greater amount of TMPT and PP $\left(\mathrm{Hyd}_{2.1}-\mathrm{Hyd}_{2.6}\right)$ show a higher rate of swelling relative to that of hydrogels with a small amount $\left(\mathrm{Hyd}_{1.1}-\mathrm{Hyd}_{1.6}\right)$, in the same time periods of swelling. This indicates that the hydrogels $\mathrm{Hyd}_{2.1}-\mathrm{Hyd}_{2.6}$ are characterized by good swelling properties relative to $\mathrm{Hyd}_{1.1}-\mathrm{Hyd}_{1.6}$. The maximum swelling was achieved at $48 \mathrm{~h}$. Also, the differences between water uptake values at 48 and $72 \mathrm{~h}$ are very low, so that $48 \mathrm{~h}$ are sufficient to achieve a maximum degree of swelling.

In Figure 3 it can be seen again that the swelling increases with the increase in TMPT and PP amount at the same absorbed dose up to a certain point when it becomes constant. It can be noticed that, for the sample that contains a higher amount of TMPT $\left(5.90 \times 10^{-3} \mathrm{~mol} / \mathrm{L}\right)$, even at the highest irradiation dose $(6.0 \mathrm{kGy})$, the swelling is around $8500 \%$, compared with the sample irradiated at the same dose, but with a lowest content of TMPT $\left(2.95 \times 10^{-3} \mathrm{~mol} / \mathrm{L}\right)$ for which the swelling is almost 
$7400 \%$. Once again, the swelling is strictly dependent on the absorbed dose and decreases when the degree of cross-linking increases.

\subsubsection{Equilibrium Water Content}

The percentage of equilibrium water content (EWC\%) is another parameter used for the assessment of hydrogels swelling and can be calculated using the following equation [34,40]:

$$
E W C=\frac{M_{S}-M_{0}}{M_{S}} \times 100
$$

where $M_{S}$ is the mass of the swollen gel at equilibrium and $M_{0}$ is the mass of the dried gel at time $t=0$.

The results are presented in Figure 4, where all samples shows values of EWC\% over 98\%, even for high irradiation doses. At the same absorbed dose, the EWC\% values of hydrogels that contain high amounts of TMPT are larger compared to those that contain small amounts. This occurs because TMPT is a hexafunctional cross-linker and its use in large amounts may form several bonds between chains [34].

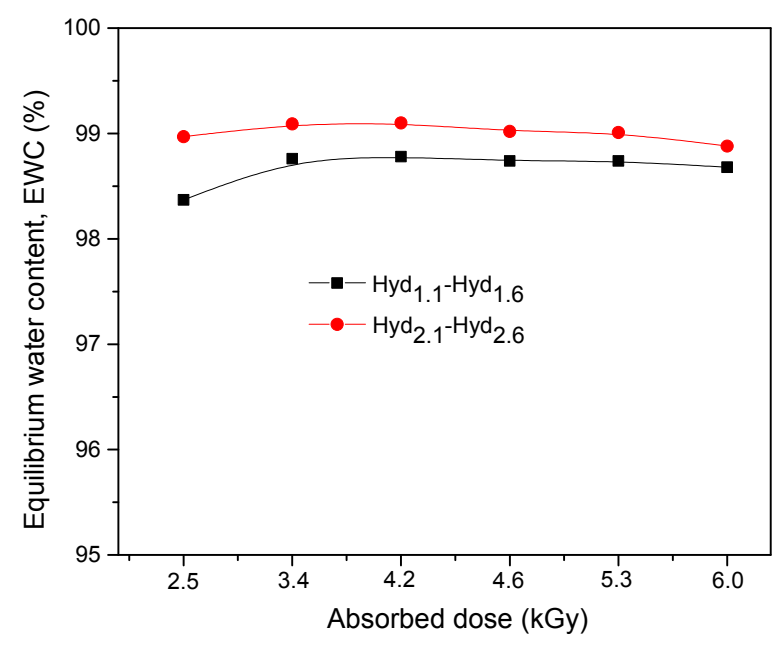

Figure 4. The effect of the absorbed dose and amount of TMPT on the equilibrium water content of hydrogels.

It is known that water holding capacity and permeability are the most important features of a hydrogel. The polar hydrophilic groups are the first to be hydrated upon contact with water, which leads to the formation of primary bound water. As a result, the network swells and exposes the hydrophobic groups, which are also capable of interacting with the water molecules. This leads to the formation of hydrophobically-bound water, also called 'secondary bound water'. Primary and secondary bound water are often combined and called 'total bound water'. The network will absorb additional water due to the osmotic driving force of the network chains towards infinite dilution. This additional swelling is opposed by the covalent or physical cross-links, leading to an elastic network retraction force. Thus, the hydrogel will reach an equilibrium swelling level. The additional absorbed water is called 'free water' or 'bulk water' and is assumed to fill the space between the network chains and/or the center of larger pores, macropores, or voids. Depending on the nature and composition of the hydrogel, the next step is disintegration and/or dissolution if the network chains or cross-links are degradable. 


\subsubsection{Swelling Kinetics}

In order to examine the controlling mechanism of the swelling processes, several kinetic models are used to test the experimental data. A simple kinetic analysis is the following first-order equation [39]:

$$
\frac{d S}{d t}=k_{1, S}\left(S_{\max .}-S\right)
$$

where $k_{1, S}$ is the rate constant of first-order swelling and $S_{\max }$. is the degree of swelling at equilibrium.

After the integration by applying the initial condition $(S=0$ at $t=0$ and $S=S$ at $t=t)$, the equation becomes:

$$
\ln W=k_{1, S} t \text {, where } W=\frac{S_{\max }}{S_{\max .}-S}
$$

A second-order equation based on swelling equilibrium degree is expressed by the following equation [39]:

$$
\frac{d S}{d t}=k_{2, S}\left(S_{\max .}-S\right)^{2}
$$

where $k_{2, S}$ is the rate constant of second-order swelling.

After integration and applying the initial condition $(S=0$ at $t=0$ and $S=S$ at $t=t)$, the equation becomes:

$$
\frac{t}{S}=A+B t
$$

where $A$ is the reciprocal of the initial swelling rate and $B$ is the inverse of the degree swelling at equilibrium:

$$
\begin{gathered}
A=r_{0}=\frac{1}{k_{2, S} \times S_{\text {max. }^{2}}} \\
B=\frac{1}{S_{\max .}}
\end{gathered}
$$

By fitting the experimental data using the first-order equation (Figure 5) and the second-order equation (Figure 6), we can calculate the swelling kinetic parameters including the rate constant of firstand second-order swelling $\left(k_{1, S}\right.$ and $\left.k_{2, S}\right)$, the theoretical degree swelling at equilibrium $\left(S_{\text {max. }}\right)$ and the initial swelling rate $\left(r_{0}\right)$, from the slope and intercept of lines. The results are listed in Tables 3 and 4 .
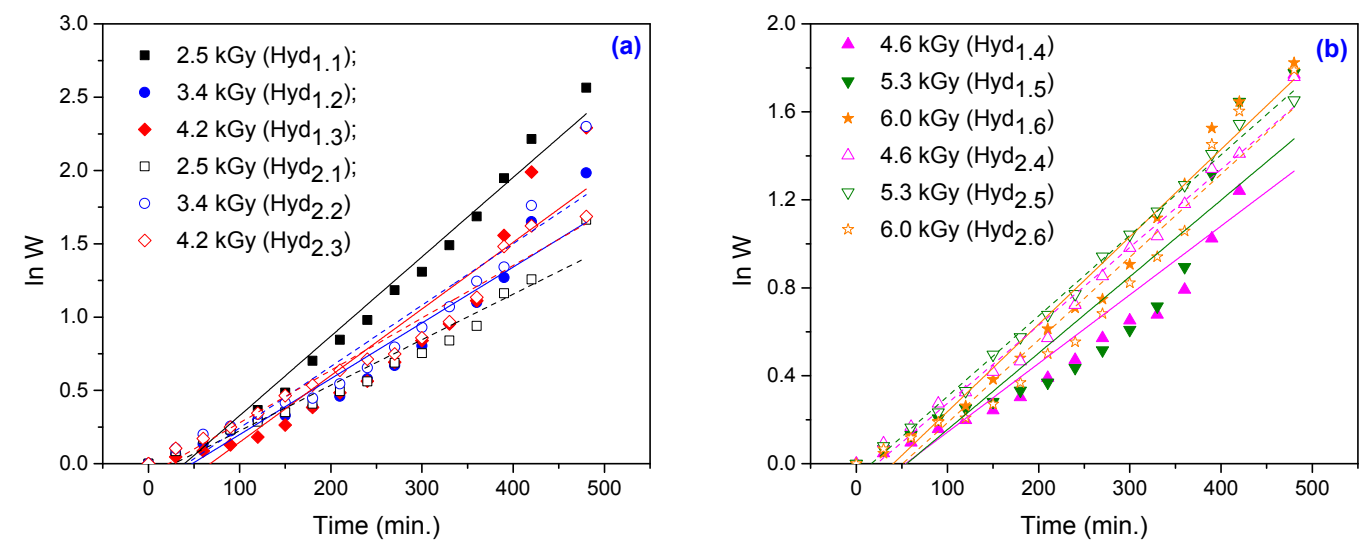

Figure 5. The first-order swelling kinetics for hydrogels obtained at: (a) $2.5 \mathrm{kGy}, 3.4 \mathrm{kGy}$ and $4.2 \mathrm{kGy}$; (b) $4.6 \mathrm{kGy}, 5.3 \mathrm{kGy}$ and $6.0 \mathrm{kGy}$. 

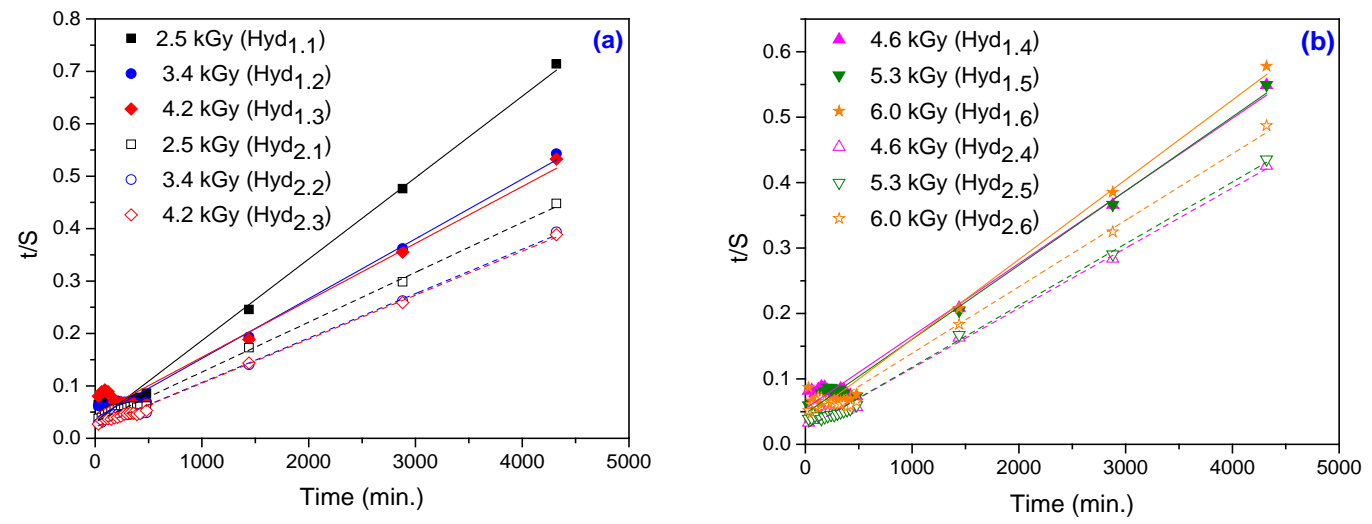

Figure 6. The second-order swelling kinetics for hydrogels obtained at: (a) $2.5 \mathrm{kGy}, 3.4 \mathrm{kGy}$ and $4.2 \mathrm{kGy}$; (b) $4.6 \mathrm{kGy}, 5.3 \mathrm{kGy}$ and $6.0 \mathrm{kGy}$.

Table 3. The variation of first-order, $k_{1, S} / \mathrm{min}^{-1}$ and second-order $k_{2, S} / \mathrm{g}_{\text {gel }} \cdot\left(\mathrm{g}_{\mathrm{water}} \cdot \mathrm{min}\right)^{-1}$ swelling rate constants with the amount of TMPT, PP and absorbed dose.

\begin{tabular}{|c|c|c|c|c|c|c|c|}
\hline \multirow{2}{*}{$\mathrm{PP}(\mathrm{mol} / \mathrm{L})$} & \multirow{2}{*}{ TMPT (mol/L) } & \multicolumn{6}{|c|}{ Absorbed Dose (kGy) } \\
\hline & & 2.5 & 3.4 & 4.2 & 4.6 & 5.3 & 6.0 \\
\hline & & \multicolumn{6}{|c|}{$k_{1, S} \times 10^{3}$} \\
\hline $3.70 \times 10^{-3}$ & $2.95 \times 10^{-3}$ & 5.42 & 3.81 & 4.55 & 3.12 & 3.48 & 3.98 \\
\hline \multirow[t]{2}{*}{$7.40 \times 10^{-3}$} & $5.90 \times 10^{-3}$ & 3.11 & 4.19 & 3.58 & 3.55 & 3.67 & 3.78 \\
\hline & & \multicolumn{6}{|c|}{$k_{2, S} \times 10^{7}$} \\
\hline $3.70 \times 10^{-3}$ & $2.95 \times 10^{-3}$ & 7.69 & 3.39 & 2.54 & 2.25 & 2.72 & 3.81 \\
\hline $7.40 \times 10^{-3}$ & $5.90 \times 10^{-3}$ & 2.88 & 3.31 & 3.26 & 3.45 & 3.76 & 2.73 \\
\hline
\end{tabular}

Table 4. The variation of initial swelling rate, $r_{0} / \mathrm{g}_{\mathrm{water}} \cdot\left(\mathrm{g}_{\mathrm{gel}} \cdot \mathrm{min}\right)^{-1}$ and equilibrium swelling degrees (theoretical) $S_{\text {max. }} / g_{\text {water }} \cdot\left(g_{\text {gel }}\right)^{-1}$ with the amount of TMPT and absorbed dose.

\begin{tabular}{|c|c|c|c|c|c|c|c|}
\hline \multirow{2}{*}{$\mathrm{PP}(\mathrm{mol} / \mathrm{L})$} & \multirow{2}{*}{ TMPT (mol/L) } & \multicolumn{6}{|c|}{ Absorbed Dose (kGy) } \\
\hline & & 2.5 & 3.4 & 4.2 & 4.6 & 5.3 & 6.0 \\
\hline & & \multicolumn{6}{|c|}{$r_{0} \times 10^{2}$} \\
\hline $3.70 \times 10^{-3}$ & $2.95 \times 10^{-3}$ & 3.13 & 3.83 & 4.62 & 5.46 & 4.71 & 3.89 \\
\hline \multirow[t]{2}{*}{$7.40 \times 10^{-3}$} & $5.90 \times 10^{-3}$ & 3.14 & 2.17 & 2.16 & 2.45 & 2.37 & 3.78 \\
\hline & & \multicolumn{6}{|c|}{$S_{\max }$} \\
\hline $3.70 \times 10^{-3}$ & $2.95 \times 10^{-3}$ & 6440 & 8768 & 9215 & 9015 & 8820 & 8207 \\
\hline $7.40 \times 10^{-3}$ & $5.90 \times 10^{-3}$ & 10,519 & 11,801 & 11,929 & 10,888 & 310,603 & 39843 \\
\hline
\end{tabular}

In Table 3 we can see that the swelling rate constants do not decrease with an increase in the amount of TMPT. This suggests that the water diffusion at higher TMPT concentrations is not hindered due to steric obstacles caused by association, which leads to a denser gel structure, as was observed in the case of hydrogels based on polysaccharides [41].

As seen in Table 4 , the initial swelling rate constant $\left(r_{0}\right)$ of the hydrogels has rapidly increased with the increase in absorbed dose for lower TMPT concentrations. At the same absorbed dose, $r_{0}$ is smaller for samples that contain a higher amount of cross-linker. The swelling properties of hydrogels containing cross-linkers are changed because the molecules of cross-linkers are placed between the chains of monomers [42]. TMPT has a high degree of functionality, rapidly undergoes addition reactions and increases the cross-linking degree of the hydrogels. The maximum equilibrium swelling 
ratios theoretically calculated are in good agreement with the equilibrium swelling ratios obtained experimentally (Figure 3).

\subsubsection{Determination of Swelling Power}

The analysis of water diffusion mechanisms in hydrogels clarifies polymer behavior and becomes important in the development of applications in biomedicine, pharmaceuticals, as well as environmental and agricultural engineering. The hydrogel swells when it is in contact with water because water diffuses, i.e., migrates into preexisting or dynamically formed spaces between the chains of hydrogels. The swelling of hydrogels involves a larger scale segmental motion, resulting, ultimately, in an increased separation between hydrogel chains. By exploiting the swelling experiment, the diffusion of water into the hydrogel can be determined. Also, by applying the following equations to $60 \%$ of swelling curves, the nature of the diffusion of water into hydrogels can be evaluated [42,43]:

$$
\begin{gathered}
F_{s w p}=\frac{M_{t}-M_{0}}{M_{0}}=k t^{n} \\
\ln F_{s w p}=n \ln t+\ln k,
\end{gathered}
$$

where $M_{t}$ and $M_{0}$ are the masses of the swollen sample at time $t$ and of the dry sample, respectively; $k$ is the swelling constant; and $n$ is the swelling exponent, which is indicative of the transport mechanism.

The swelling-time curves of hydrogels in water are used to calculate the diffusion coefficients $(D)$ by the short time approximation method. This method is valid only for the first $60 \%$ of the swelling [39]. The diffusion coefficients have been calculated using the following equation:

$$
F=4\left[\frac{D}{\pi \times r^{2}}\right]^{1 / 2} t^{1 / 2}
$$

where $D$ is in $\mathrm{cm}^{2} \cdot \mathrm{sec}^{-1}, t$ in sec and $r$ is the radius of the cylindrical polymer sample $(\mathrm{cm})$.

For the hydrogels obtained in this study, $\ln F$ versus $\ln t$ are plotted and shown in Figure 7 and the graphs of $F$ versus $t^{1 / 2}$ are shown in Figure 8. The swelling constant $(k)$, swelling exponent $(n)$ and diffusion coefficients $(D)$ are calculated from the slopes and intercepts of the lines, respectively and are listed in Table 5.
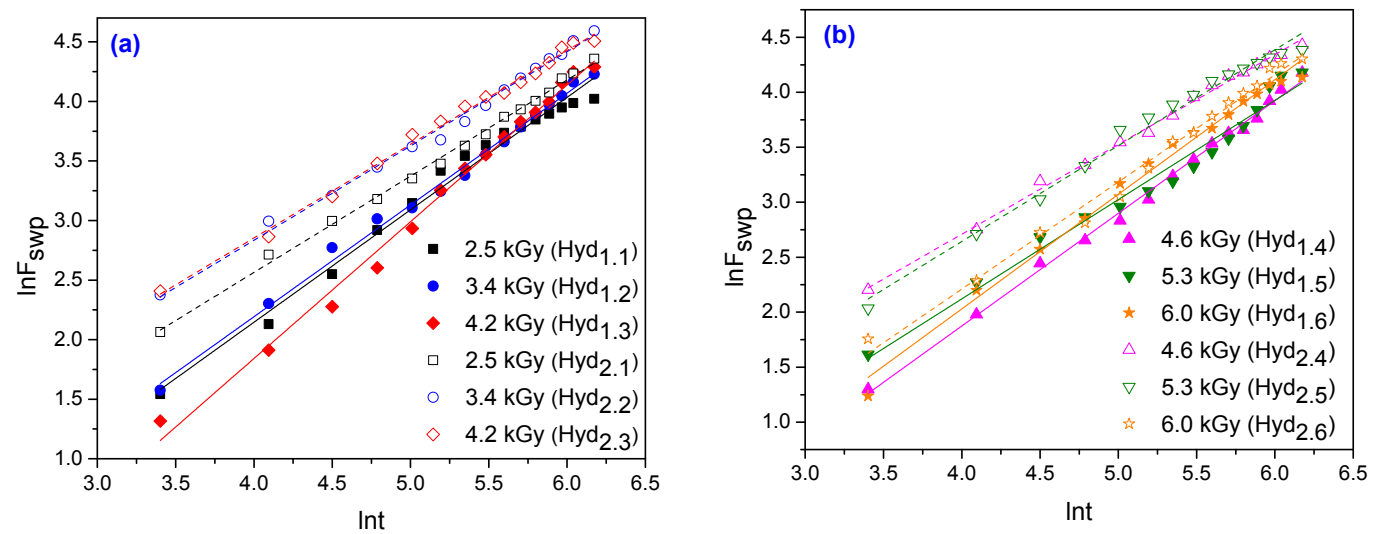

Figure 7. The plots of $\ln F$ versus $\ln t$ for hydrogels obtained at: (a) $2.5 \mathrm{kGy}, 3.4 \mathrm{kGy}$ and $4.2 \mathrm{kGy}$; (b) $4.6 \mathrm{kGy}, 5.3 \mathrm{kGy}$ and $6.0 \mathrm{kGy}$. 

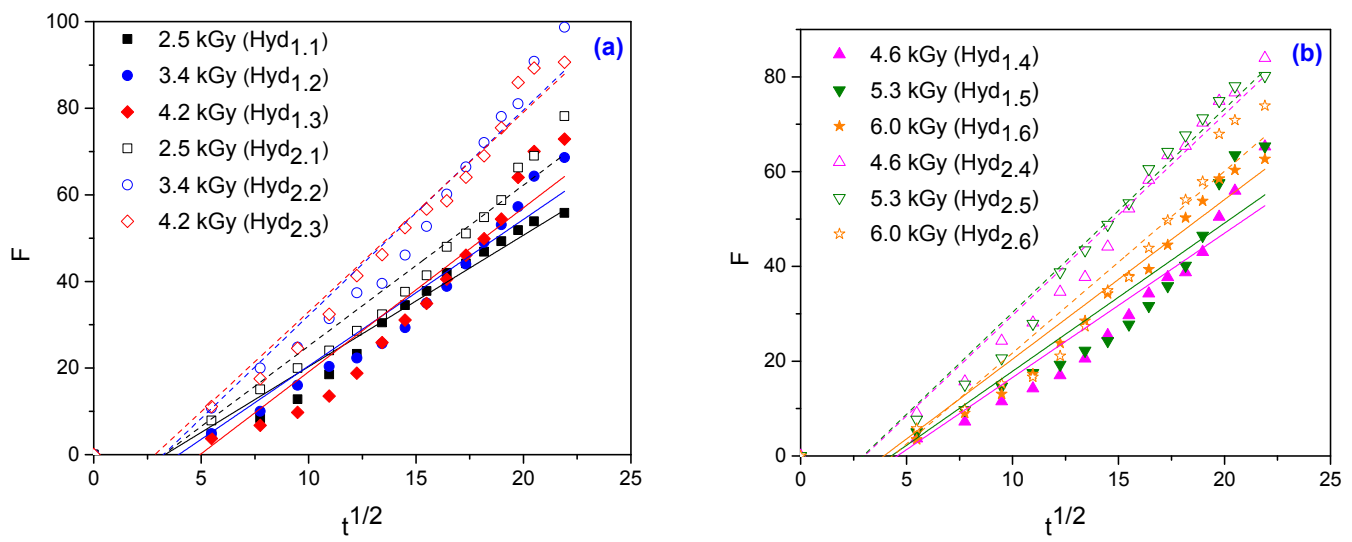

Figure 8. Plots of F versus $t^{1 / 2}$ for hydrogels obtained at: (a) $2.5 \mathrm{kGy}, 3.4 \mathrm{kGy}$ and $4.2 \mathrm{kGy}$; (b) $4.6 \mathrm{kGy}$, $5.3 \mathrm{kGy}$ and $6.0 \mathrm{kGy}$.

Table 5. The variation of $n, k$ and diffusional coefficient $\left(D \times 10^{-3} / \mathrm{cm}^{2} \cdot \mathrm{sec}^{-1}\right)$ with the amount of TMPT and absorbed dose.

\begin{tabular}{|c|c|c|c|c|c|c|c|}
\hline \multirow{2}{*}{$\mathrm{PP}(\mathrm{mol} / \mathrm{L})$} & \multirow{2}{*}{ TMPT (mol/L) } & \multicolumn{6}{|c|}{ Absorbed Dose (kGy) } \\
\hline & & 2.5 & 3.4 & 4.2 & 4.6 & 5.3 & 6.0 \\
\hline & & \multicolumn{6}{|c|}{$n$} \\
\hline $3.70 \times 10^{-3}$ & $2.95 \times 10^{-3}$ & 0.94 & 0.93 & 1.15 & 1.02 & 0.90 & 0.98 \\
\hline \multirow[t]{2}{*}{$7.40 \times 10^{-3}$} & $5.90 \times 10^{-3}$ & 0.81 & 0.79 & 0.79 & 0.82 & 0.87 & 0.97 \\
\hline & & \multicolumn{6}{|c|}{$k$} \\
\hline $3.70 \times 10^{-3}$ & $2.95 \times 10^{-3}$ & 0.20 & 0.21 & 0.06 & 0.11 & 0.23 & 0.12 \\
\hline \multirow[t]{2}{*}{$7.40 \times 10^{-3}$} & $5.90 \times 10^{-3}$ & 0.51 & 0.72 & 0.75 & 0.57 & 0.43 & 0.18 \\
\hline & & \multicolumn{6}{|c|}{$D \times 10^{3}$} \\
\hline $3.70 \times 10^{-3}$ & $2.95 \times 10^{-3}$ & 0.31 & 0.49 & 0.77 & 0.59 & 0.73 & 0.96 \\
\hline $7.40 \times 10^{-3}$ & $5.90 \times 10^{-3}$ & 1.46 & 2.62 & 2.69 & 2.46 & 2.72 & 2.31 \\
\hline
\end{tabular}

According to the relative rates of diffusion $\left(\mathrm{R}_{\text {diff }}\right)$ and relaxation $\left(\mathrm{R}_{\text {relax }}\right)$, there are three classes of diffusion [44-46]: Case I: $n=0.45-0.5$ indicates a Fickian diffusion mechanism, in which the rate of diffusion is much smaller than the rate of relaxation $\left(R_{\text {diff }}<<R_{\text {relax }}\right)$ and the system is controlled by diffusion; Case II: $n=1.0$, where the diffusion process is much faster than the relaxation process $\left(R_{\text {diff }}>>R_{\text {relax }}\right)$ and the system is controlled by relaxation; Case III: $0.5<n<1.0$ indicates non-Fickian (anomalous) diffusion mechanism, which describes those cases where the diffusion and relaxation rates are comparable $\left(\mathrm{R}_{\text {diff }} \approx \mathrm{R}_{\text {relax }}\right)$. Occasionally, when $n>1$, the situation is regarded as Super Case II kinetics [44,47,48].

In Table 5 it can be noted that the values of the swelling coefficient $(n)$ vary between 0.7 and 1.15. Based on the results, it can be said that the diffusion of water into the obtained hydrogels shows a non-Fickian character, with two exceptions: $\mathrm{Hyd}_{1.3}$ and $\mathrm{Hyd}_{1.4}$, for which the diffusion of water shows Super Case II kinetics. When the diffusion type involves anomalous behavior, the relaxation and diffusion times are of the same order of magnitude. For a non-Fickian diffusion mechanism, the cross-linking density is high, thus leading to a small amount of bulk water and a decreased diffusion rate [49-51]. It is known that the high water content of hydrogels is represented by the bulk water, which is similar with the bulk water coming from outside of the gel. In a polymeric network of hydrogels, there are at least three types of water structures, as follows: bulk water, primary and secondary bound water. When a hydrogel is immersed in water, the first type of water that will be present is the primary bound water, due to the hydration of hydrophilic groups of the polymer. The 
primary bound water is very difficult to remove from the gel. As a result, the network swells and the hydrophobic groups are exposed, leading to the formation of secondary bound water [51].

For two of the samples $\left(\operatorname{Hyd}_{1.3}\right.$ and $\left.\mathrm{Hyd}_{1.4}\right)$, the swelling exponent $(n)$ is higher than 1.0, which indicates that the transport mechanism is Super Case II or Case II (relaxation controlled). Penetration of water molecules is much greater than in the relaxation processes. The swelling exponent $(n)$ slightly increased as a function of absorbed dose (up to $4.2 \mathrm{kGy}$ ) and decreased as the amount of TMPT increases. The diffusion coefficient $(D)$ has the same tendency: it increases as a function of absorbed dose up to $4.2 \mathrm{kGy}$, followed by a slightly decrease, but increases as the amount of TMPT increases. This phenomenon has been attributed to the ease with which water molecules can diffuse into a hydrogel network [51].

\subsubsection{Network Studies}

Directly related to the polymer cross-link density is $M_{c}$, the average molar mass between cross-links, which is determined using the swelling equilibrium. According to the theory of Flory and Rehner for a perfect network, $M_{c}$ is calculated using the following equation [39]:

$$
M_{c}=-V_{1} d_{p} \frac{v_{S}^{1 / 3}-v_{S} / 2}{\ln \left(1-v_{S}\right)+v_{S}+\chi v_{S}^{2}}
$$

where $V_{1}$ is the molar volume of the solvent (in this case water: $18.1 \mathrm{~cm}^{3} \cdot \mathrm{mol}^{-1}$ ); $d_{P}$ is the polymer density $\left(1.106 \mathrm{~g} \cdot \mathrm{cm}^{-3}\right) ; v_{S}$ is the volume fraction of the polymer in the swollen gel $\left(\mathrm{cm}^{3}\right)$ and is equal to $1 / S$; and $\chi$ is the Flory-Huggins interaction parameter between the solvent and polymer.

The value of $\chi$ is calculated as follows [52-54]:

$$
\chi=0.431-0.311 \times v_{S}-0.036 v_{S}^{2}
$$

The cross-link density $q$ is defined as being the mole fraction of the cross-linked units:

$$
q=\frac{M_{0}}{M_{c}}
$$

where $M_{0}$ is the molecular weight of the repeating units from polymer and is calculated by the following equation [52,54]:

$$
M_{0}=\frac{\left(m_{A M D} \times M_{A M D}\right)+\left(m_{A A} \times M_{A A}\right)+\left(m_{T M P T} \times M_{T M P T}\right)}{m_{A M D}+m_{A A}+m_{T M P T}}
$$

where $m_{A M D}, m_{A A}$ and $m_{T M P T}$ are the masses of acrylamide, acrylic acid and cross-linker (TMPT), expressed in grams; and $M_{A M D}, M_{A A}$ and $M_{T M P T}$ are the molar masses of acrylamide, acrylic acid and TMPT, expressed in $\mathrm{g} \cdot \mathrm{mol}^{-1}$.

Other important parameters used for the assessment of networks are gel pore or mesh size $(\xi)$ and porosity $(P \%)$. The mesh size is related to the space available for the transport of a solute or solvent in a network. An increase in the mesh size and porosity results in an increase in the water content in the hydrogel. Using the calculated values of number average molecular mass between cross-links, $M_{\mathcal{C}}$, the mesh size, was determined by the following equation [55]:

$$
\xi=v_{S}^{-1 / 3} \times l \times \sqrt{\frac{2 \times C_{n} \times M_{c}}{M_{0}}}
$$

where $v_{S}$ is the volume fraction of the polymer in the swollen gel, $l$ is the length of the $\mathrm{C}-\mathrm{C}$ bond along the polymer backbone $(0.154 \mathrm{~nm}), C_{n}$ is the Flory characteristic ratio of the polymer and $M_{r}$ is the molecular mass of the repeated unit. The characteristic ratio $C_{n}$ for poly(AMD-co-AA) hydrogels was 
considered as the weighted average of $C_{n}$ values for poly(AMD) and poly(AA) chains, according to their molar ratio in the hydrogel $\left(C_{n}\right.$ was 8.8 for poly(AMD) and 6.7 for poly(AA)).

The porosity $P(\%)$ of the obtained hydrogels was determined using the following equation [39]:

$$
P(\%)=\frac{V_{d}}{1-V_{d}} \times 100
$$

where $V_{d}$ is the volume ratio of water at equilibrium.

The values of the number-average molar mass between cross-links $\left(M_{\mathcal{c}} / \mathrm{g} \cdot \mathrm{mol}^{-1}\right)$, cross-link density $(q)$, mesh size $(\xi)$ and porosity $(P)$ are shown in Table 6.

Table 6. The variation of the number-average molar mass between cross-links $\left(\mathrm{M}_{\mathrm{c}} / \mathrm{g} \cdot \mathrm{mol}^{-1}\right)$, cross-link density $(q)$, mesh size $(\xi)$ and porosity $(P)$ with the amount of TMPT, PP and absorbed dose.

\begin{tabular}{|c|c|c|c|c|c|c|c|}
\hline \multirow{2}{*}{$\mathrm{PP}(\mathrm{mol} / \mathrm{L})$} & \multirow{2}{*}{ TMPT (mol/L) } & \multicolumn{6}{|c|}{ Absorbed Dose (kGy) } \\
\hline & & 2.5 & 3.4 & 4.2 & 4.6 & 5.3 & 6.0 \\
\hline & & \multicolumn{6}{|c|}{$M_{c} \times 10^{-3}$} \\
\hline $3.70 \times 10^{-3}$ & $2.95 \times 10^{-3}$ & 179 & 184 & 190 & 176 & 179 & 164 \\
\hline \multirow[t]{2}{*}{$7.40 \times 10^{-3}$} & $5.90 \times 10^{-3}$ & 625 & 668 & 684 & 582 & 559 & 458 \\
\hline & & \multicolumn{6}{|c|}{$q \times 10^{4}$} \\
\hline $3.70 \times 10^{-3}$ & $2.95 \times 10^{-3}$ & 4.013 & 3.916 & 3.783 & 4.089 & 4.001 & 4.391 \\
\hline \multirow[t]{2}{*}{$7.40 \times 10^{-3}$} & $5.90 \times 10^{-3}$ & 1.160 & 1.086 & 1.061 & 1.246 & 1.297 & 1.583 \\
\hline & & \multicolumn{6}{|c|}{$\xi / \mathrm{nm}$} \\
\hline $3.70 \times 10^{-3}$ & $2.95 \times 10^{-3}$ & 107 & 138 & 142 & 135 & 137 & 128 \\
\hline \multirow[t]{2}{*}{$7.40 \times 10^{-3}$} & $5.90 \times 10^{-3}$ & 258 & 293 & 298 & 266 & 258 & 226 \\
\hline & & \multicolumn{6}{|c|}{$P(\%)$} \\
\hline $3.70 \times 10^{-3}$ & $2.95 \times 10^{-3}$ & 98.73 & 98.74 & 98.77 & 98.71 & 98.73 & 98.66 \\
\hline $7.40 \times 10^{-3}$ & $5.90 \times 10^{-3}$ & 99.05 & 99.09 & 99.10 & 99.01 & 98.99 & 98.87 \\
\hline
\end{tabular}

The average molecular weight between cross-links $\left(M_{\mathcal{C}}\right)$, cross-linking density $(q)$ and the network mesh size $(\xi)$ determined from equilibrium swelling experiments are major parameters in defining the structure of a cross-linked hydrogel network.

$M_{c}$ features the number average molecular weight of polymer chains between two adjacent cross-link junctions. This parameter allows the degree of cross-linking of hydrogel samples to be measured and expressed as $q$. As is shown in Table 6, the number-average molar mass between cross-links of hydrogels has increased with the increase in the amount of cross-linker (TMPT). For both TMPT amounts, with the increasing of the irradiation dose, Mc increased up to a maximum at $4.2 \mathrm{kGy}$ and then decreased. Due to the increase of the cross-linker concentration, the $M_{\mathcal{C}}$ between the two main backbones increases. A large value of $M_{\mathcal{C}}$ indicates long chains between the two backbones. The obtained results show that the $M_{c}$ values are affected by the absorbed dose. The increase in absorbed doses leads to a decrease in $M_{c}$ since the hydrogel becomes more and more dense. However, AMD includes several hydrophilic fragments and thus the hydrogels shows a high degree of swelling. The values of the cross-link density are inversed due to the value of number-average molar mass between cross-links. An increase in the amount of cross-linker increases the cross-linking density and decreases the swelling (Figure 2). This confirmed the role of TMPT as a cross-linking agent. The mesh size $(\xi)$, sometimes referred as pore size, indicates the distance between two adjacent cross-links. It is critical in controlling the water or aqueous solutions of various salts and heavy metals' diffusion rate as it reflects the amount of space available for a salt or heavy metal molecule to diffuse in or out of the swollen hydrogel network. The mesh size and porosity have decreased with the increase in the amount of cross-linker (TMPT) and the absorbed dose. More than that, from the results obtained it can be 
observed that the degree of cross-linking had a significant influence on the mesh size. Hydrogels having a higher degree of cross-linking have a relatively shorter distance between two cross-linking points and, as a result, the mesh sizes and porosity of these hydrogels are lower [55].

\subsubsection{Spectral Characterization}

To understand the binding of AMD, AA and TMPT in hydrogels during irradiation, we evaluated the FTIR spectra of hydrogels obtained at 2.5 and $6.0 \mathrm{kGy}$ (Figure 9). The broad bands in the range of 3345 to $3330 \mathrm{~cm}^{-1}$ are attributed to the symmetric and asymmetric $-\mathrm{NH}$ stretching vibrations of AMD and the broad bands in the region of $3200-3190 \mathrm{~cm}^{-1}$ are characteristic of the absorptions of $-\mathrm{OH}$ groups of AA. The methylene group vibrations are used to monitor the extent of polymerization. The absorbance in the range $2937-2933 \mathrm{~cm}^{-1}$ is assigned to the asymmetrical stretching vibrations of $-\mathrm{CH}_{2}$ from AMD or AA [56,57]. The bands in the range $1774-1785 \mathrm{~cm}^{-1}$ correspond to the carbonyl stretching vibration of $\mathrm{C}=\mathrm{O}$ connected to the carboxyl group, but in the range of $1647-1657 \mathrm{~cm}^{-1} \mathrm{can}$ be attributed to the $\mathrm{C}=\mathrm{O}$ group connected to the amide group [56].
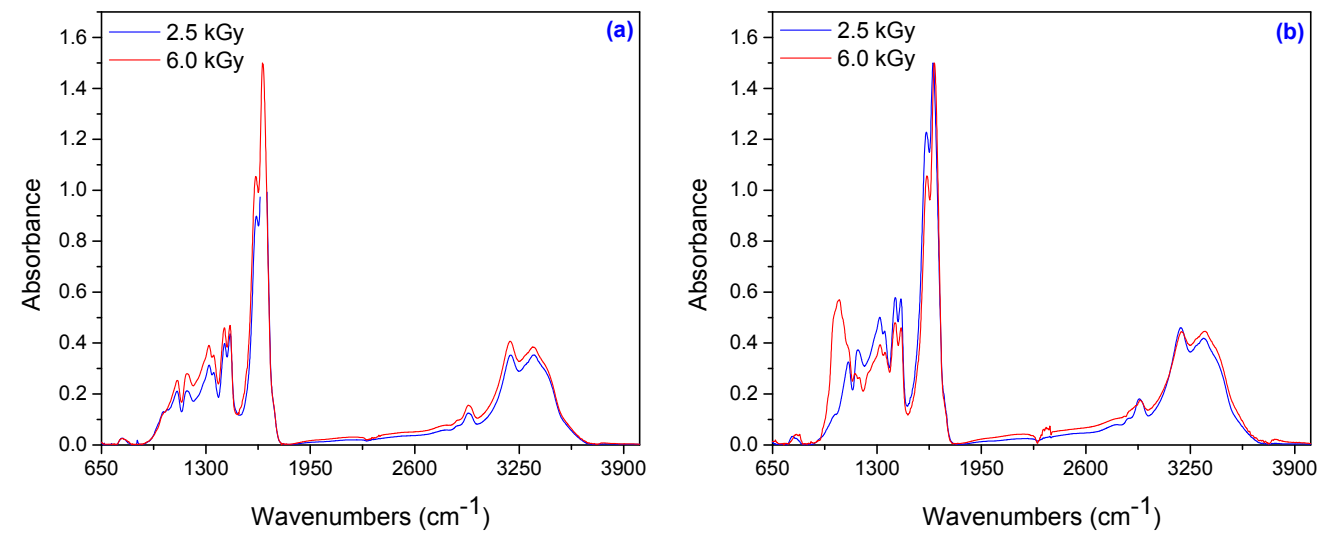

Figure 9. FTIR spectra in the range of $650-4000 \mathrm{~cm}^{-1}$ for samples obtained at $2.5 \mathrm{kGy}$ and $6.0 \mathrm{kGy}:(\mathbf{a}) 3.70 \times 10^{-3} \mathrm{~mol} / \mathrm{L} \mathrm{PP}$ and $2.95 \times 10^{-3} \mathrm{~mol} / \mathrm{L} \mathrm{TMPT} ;(\mathbf{b}) 7.40 \times 10^{-3} \mathrm{~mol} / \mathrm{L} \mathrm{PP}$ and $5.90 \times 10^{-3} \mathrm{~mol} / \mathrm{L}$ TMPT.

The characteristic band that appeared in the range of $1600-1620 \mathrm{~cm}^{-1}$ is due to the amide II bands. Amide II results from the $\mathrm{N}-\mathrm{H}$ bending vibration and from the $\mathrm{C}-\mathrm{N}$ stretching vibration. Symmetric stretching of $\mathrm{COO}^{-}$is found at $1450-1410 \mathrm{~cm}^{-1}$ in the poly(acrylamide-co-acrylic acid) spectra [56]. On the other hand, the bands at $1443 \mathrm{~cm}^{-1}$ and $1353 \mathrm{~cm}^{-1}$ are attributed to $\mathrm{CH}_{2}$ bending and $-\mathrm{CH}$ bending vibrations, respectively. For the polyacrylamide, the $-\mathrm{CN}$ stretching appears at $1350-1345 \mathrm{~cm}^{-1}$ and $-\mathrm{C}-\mathrm{O}$ stretching at $1125-1116 \mathrm{~cm}^{-1}$. The $\mathrm{C}-\mathrm{O}-\mathrm{C}$ asymmetric stretching and $\mathrm{C}-\mathrm{O}$ stretching from AA are confirmed with the absorptions around $1190-1180 \mathrm{~cm}^{-1}$ and $1065-1025 \mathrm{~cm}^{-1}$, respectively [58].

\subsubsection{SEM Analysis}

The technique of Scanning Electron Microscopy was used for observing the surface appearance and the structure of copolymers. The scanning electron micrographs of hydrogels obtained at $2.5 \mathrm{kGy}$ and $6.0 \mathrm{kGy}$ irradiation doses are shown in Figures 10 and 11. 


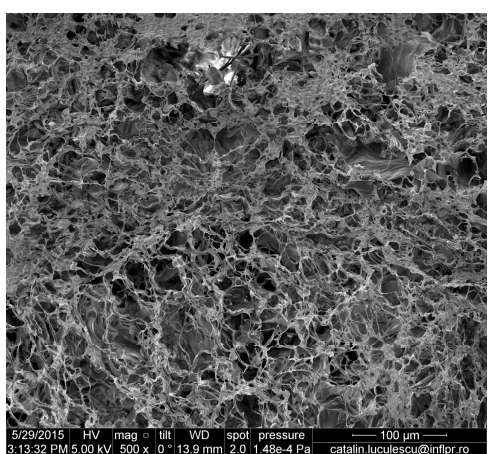

(a)

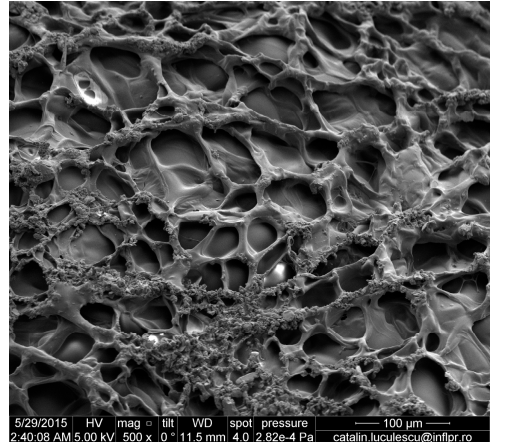

(b)

Figure 10. Scanning electron micrographs of hydrogels with $3.70 \times 10^{-3} \mathrm{~mol} / \mathrm{L} \mathrm{PP}$ and $2.95 \times 10^{-3} \mathrm{~mol} / \mathrm{L}$ TMPT obtained by electron beam irradiation at (a) $2.5 \mathrm{kGy}$ and (b) $6.0 \mathrm{kGy}$.

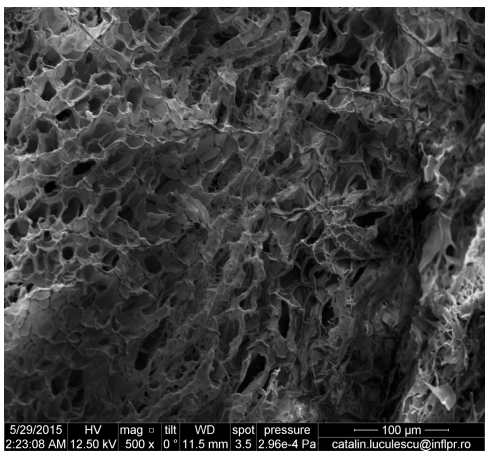

(a)

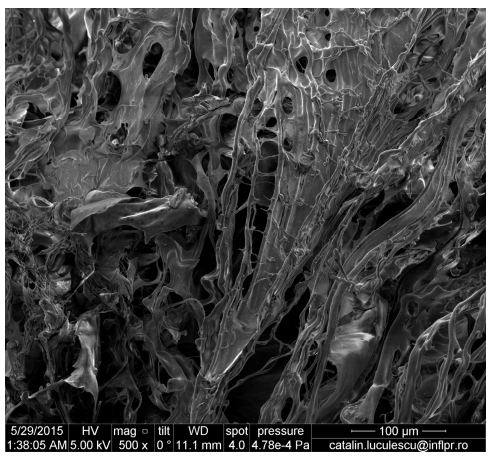

(b)

Figure 11. Scanning electron micrographs of hydrogels with $7.40 \times 10^{-3} \mathrm{~mol} / \mathrm{L} \mathrm{PP}$ and $5.90 \times 10^{-3} \mathrm{~mol} / \mathrm{L}$ TMPT obtained by electron beam irradiation at (a) $2.5 \mathrm{kGy}$ and (b) $6.0 \mathrm{kGy}$.

The cross-link density and composition affect the microstructure of hydrogels, which influences the swelling characteristics. In Table 6 it is observed that the cross-link density has increased with the increase in the amount of PP, TMPT and absorbed dose. On the other hand, the mesh size has decreased with the increase in the amount of PP, TMPT and absorbed dose. So, as can be seen in Figures 10 and $11(\mathrm{a}$ and $\mathrm{b})$, the hydrogels with a small amount of PP and TMPT $\left(3.70 \times 10^{-3} \mathrm{~mol} / \mathrm{L}\right.$ and $2.95 \times 10^{-3} \mathrm{~mol} / \mathrm{L}$ TMPT, respectively) have presented a more open and porous channel structure than the hydrogels with a high content of PP and TMPT $\left(7.40 \times 10^{-3} \mathrm{~mol} / \mathrm{L}\right.$ PP and $5.90 \times 10^{-3} \mathrm{~mol} / \mathrm{L}$ TMPT, respectively) for the same irradiation dose. These pores facilitate the transport of water [59-61] and the hydrogels $\mathrm{Hyd}_{1.1}$ and $\mathrm{Hyd}_{1.6}$ obtained at $2.5 \mathrm{kGy}$ and $6 \mathrm{kGy}$, respectively, show the highest equilibrium water uptake $(14,200 \%$ and $12,100 \%$, respectively). With the increase in the amounts of PP and TMPT, the morphology of the hydrogels is changing (Figure 11). The SEM micrographs of the hydrogels obtained at $2.5 \mathrm{kGy}$ and $6 \mathrm{kGy}\left(\mathrm{Hyd}_{2.1}\right.$ and $\left.\mathrm{Hyd}_{2.6}\right)$ present an irregular surface with a semi-porous structure, with macro- and micropores within the hydrogels and show the lowest equilibrium water uptake ( $8200 \%$ and $7400 \%$, respectively).

\subsection{Metal Ion Uptake Studies}

Uptake experiments of metal ions at different $\mathrm{pH}$ were carried out by placing for $72 \mathrm{~h}$ at room temperature $\left(25 \pm 0.1^{\circ} \mathrm{C}\right)$ portions of $0.5 \mathrm{~g}$ of dried hydrogels in a series of flasks containing $100 \mathrm{~mL}$ aqueous solutions of $\mathrm{Cu}^{2+}$ and $\mathrm{Cr}^{6+}$ with an initial concentration of $500 \mathrm{mg} \cdot \mathrm{L}^{-1}$. The $\mathrm{pH}$ was adjusted using $0.1 \mathrm{M} \mathrm{NaOH}$ and $0.1 \mathrm{M} \mathrm{HCl}$. The effect of a heavy metal solution $\left(\mathrm{Cu}^{2+}\right.$ and $\left.\mathrm{Cr}^{6+}\right)$ on the swellability of the investigated hydrogels $\left(\mathrm{Hyd}_{1.1}-\mathrm{Hyd}_{1.6}\right.$ and $\left.\mathrm{Hyd}_{2.1}-\mathrm{Hyd}_{2.6}\right)$ was studied. 
$\mathrm{pH}$ is an important parameter for hydrogels in the adsorption of metals ions. It affects the electronic status of the pendant functional groups, such as protonation-deprotonation of the basic groups, as well as dissociation-association of the acidic groups. In addition, it may also modify the oxidation form of the metal ions present in the medium [62].

The effect of $\mathrm{pH}$ on the swelling properties of the PAM-PAA hydrogel is shown in Figures 12 and 13. The swelling values of hydrogels in a heavy metal solution of $\mathrm{pH} 7$ is found to be significantly higher than those in a solution of $\mathrm{pH} 2$. The swelling mostly occurred from $\mathrm{pH} 3$ to 7. It is well known that the swelling of the hydrogel is induced by the electrostatic repulsion of the ionic charges of its network [63].
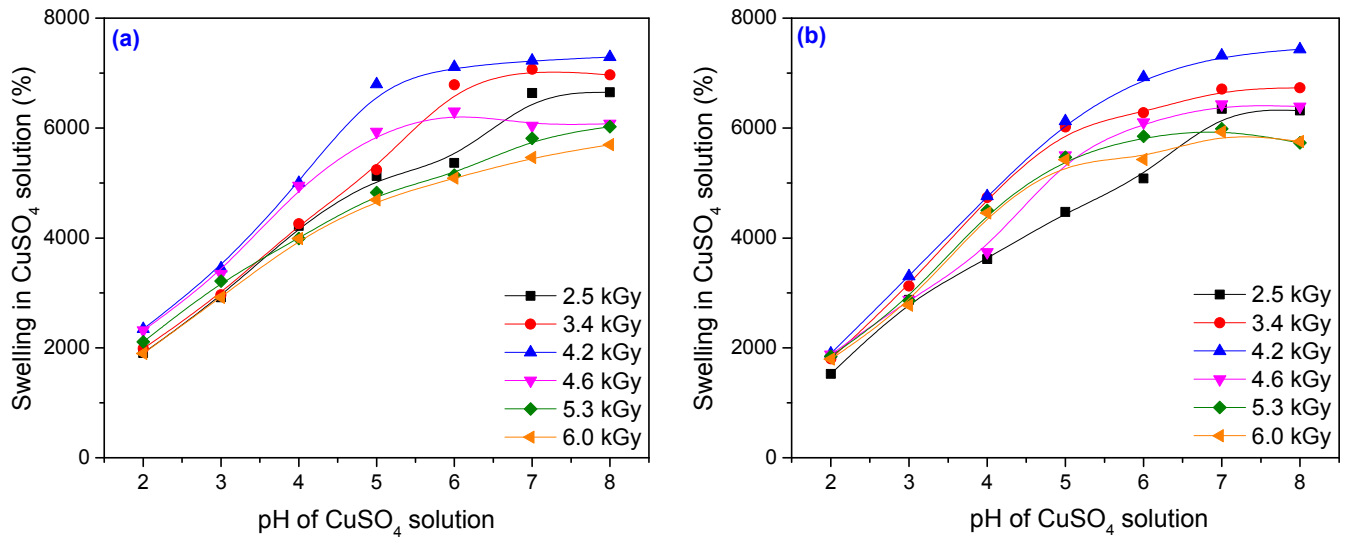

Figure 12. Swelling of the hydrogels in $\mathrm{CuSO}_{4}$ solution as a function of $\mathrm{pH}, \mathrm{PP}$ and TMPT amount: (a) $3.70 \times 10^{-3} \mathrm{~mol} / \mathrm{L} \mathrm{PP}$ and $2.95 \times 10^{-3} \mathrm{~mol} / \mathrm{L} \mathrm{TMPT}$; (b) $7.40 \times 10^{-3} \mathrm{~mol} / \mathrm{L} \mathrm{PP}$ and $5.90 \times 10^{-3} \mathrm{~mol} / \mathrm{L} \mathrm{TMPT}$.
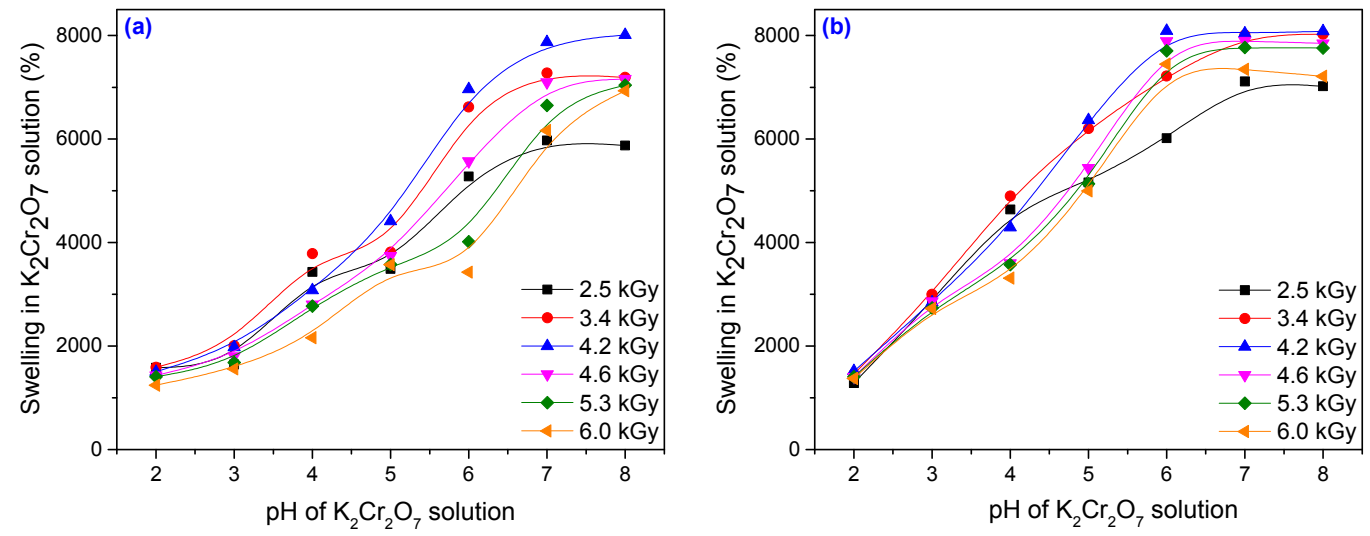

Figure 13. Swelling of the hydrogels in $\mathrm{K}_{2} \mathrm{Cr}_{2} \mathrm{O}_{7}$ solution as a function of $\mathrm{pH}, \mathrm{PP}$ and TMPT amount: (a) $3.70 \times 10^{-3} \mathrm{~mol} / \mathrm{L} \mathrm{PP}$ and $2.95 \times 10^{-3} \mathrm{~mol} / \mathrm{L} \mathrm{TMPT}$; (b) $7.40 \times 10^{-3} \mathrm{~mol} / \mathrm{L} \mathrm{PP}$ and $5.90 \times 10^{-3} \mathrm{~mol} / \mathrm{L} \mathrm{TMPT}$.

At $\mathrm{pH}>7$ the change in equilibrium swelling ratio with $\mathrm{pH}$ was superficial. A fully hydrated gel sample was almost 80 times heavier than a dried gel for $\mathrm{pH}>6$. At $\mathrm{pH}<3$ the degree of swelling was very low. When the hydration was carried out in a solution of $\mathrm{pH}<3$, the carboxylic acid groups on the copolymer backbone were converted to the protonated acid form [64]. At an acidic $\mathrm{pH}$, most of the carboxylate anions are protonated, so the main anion-anion repulsive forces are eliminated and consequently swelling values are decreased. In addition, there are H-bonding interactions between the carboxylic groups of acrylic acid and the amide groups of acrylamide. These $\mathrm{H}$-bonding interactions result in the formation of a compact or tight structure that does not permit 
much movement of polymeric chains within the hydrogel network, which leads to a minimum swelling of the hydrogel [63]. A low swelling ratio indicated that the water content for the acid form of the hydrogel was low. When the solution $\mathrm{pH}$ was above 6, the carboxylic groups on the copolymer backbone were converted to the salt (basic) form and the maximum degree of swelling was achieved. When the hydration occurred in a solution within the $\mathrm{pH}$ range 3-6, an almost linear relationship between the swelling ratio and $\mathrm{pH}$ was observed. Within this $\mathrm{pH}$ range, the acid and salt forms of the carboxylic groups on the copolymer backbone are both present [64]. As the $\mathrm{pH}$ of the swelling medium increased, ionization of the carboxylic acid groups of the gel occurred. That resulted in a more hydrophilic polymer network and contributed to higher water absorption as the $\mathrm{pH}$ increased [63]. Generally, it can be observed that the swellability of the hydrogel decreased in the heavy metal solution relative to double-distilled water. In the case of a heavy metal solution, the observed decrease in the swellability can be explained on the basis of complex formation. The interaction between metal ions and both carboxylate and amino (of amide) groups through coordination gives birth to a highly cross-linked network with small free volume inside the gel [65].

In Figures 12 and 13 it can be seen that for both types of metal ion solutions, the swelling has increased with the increase in the absorbed dose, reaching a maximum and then decreasing. The best results, meaning the highest swelling, were obtained for a sample irradiated at $4.2 \mathrm{kGy}$. After $72 \mathrm{~h}$, the filtrate of samples $\mathrm{Hyd}_{1.3}$ and $\mathrm{Hyd}_{2.3}$ obtained at $4.2 \mathrm{kGy}$ was measured for metal ion concentration using an atomic absorption spectrometer (AAS). Every value reported was the mean of five measurements and the standard deviation was less than $5 \%$. The amount of metal ion adsorbed was calculated using the equation [66]:

$$
Q=\frac{C_{0}-C_{72}}{m} \times V
$$

where $Q$ is the adsorbed amount of heavy metal ions $(\mathrm{mg} / \mathrm{g}) ; C_{0}$ and $C_{72}$ are the concentrations of metal ions in aqueous phase before and after treatment $(\mathrm{mg} / \mathrm{L}) ; V$ is the volume of the aqueous phase $(L)$; and $m$ is the amount of dry hydrogel (g).

The adsorption of $\mathrm{Cu}^{2+}$ and $\mathrm{Cr}^{6+}$ in $\mathrm{Hyd}_{1.3}$ and $\mathrm{Hyd}_{2.3}$ hydrogels after $72 \mathrm{~h}$ atvarious $\mathrm{pH}$ values is represented in Figure 14.
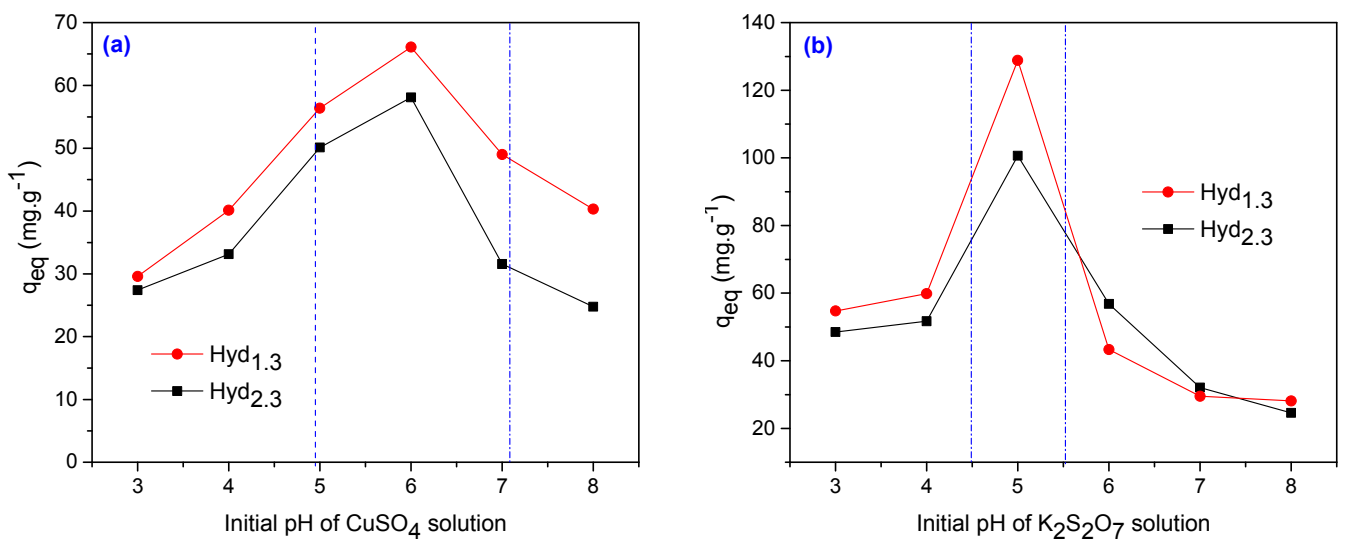

Figure 14. Effect of $\mathrm{pH}$ on (a) $\mathrm{Cu}^{2+}$ and (b) $\mathrm{Cr}^{6+}$ adsorption in $\mathrm{Hyd}_{1.3}$ and $\mathrm{Hyd}_{2.3}$ hydrogels (initial concentration: $\mathrm{Cu}^{2+}$ and $\mathrm{Cr}^{6+} 500 \mathrm{mg} \cdot \mathrm{L}^{-1}$, dose: $0.5 \mathrm{~g}$; volume $100 \mathrm{~mL}$ ).

Figure 14a clearly shows the effects of the initial $\mathrm{pH}(3.0-8.0)$ on the adsorption capacity of $\mathrm{Cu}^{2+}$ for both hydrogels $\left(\mathrm{Hyd}_{1.3}\right.$ and $\left.\mathrm{Hyd}_{2.3}\right)$. From this figure, it is evident that the amounts of $\mathrm{Cu}^{2+}$ adsorption mainly depend on the $\mathrm{pH}$ values of the metal solution. The uptake of $\mathrm{Cu}^{2+}$ was found at a gradual increase from $\mathrm{pH}$ 3.0-4.0, beyond which the values sharply increase from 4.0 to 5.0 and the highest adsorption $\mathrm{pH}$ value is at 6.0. This may be because of the protonation of $-\mathrm{NH}_{2}$ from the 
acrylamide groups and the corresponding $-\mathrm{OH}$ in the acrylic acid under acidic conditions, generating repulsive charges between these functional groups and $\mathrm{Cu}^{+2}$ ions. The $\mathrm{Cu}^{+2}$ absorption at $\mathrm{pH} 6.0$ was $66 \mathrm{mg} / \mathrm{g}$ for the $\mathrm{Hyd}_{1.3}\left(3.70 \times 10^{-3} \mathrm{~mol} / \mathrm{L} \mathrm{PP}\right.$ and $\left.2.95 \times 10^{-3} \mathrm{~mol} / \mathrm{L} \mathrm{TMPT}\right)$ and $58 \mathrm{mg} / \mathrm{g}$ for the $\mathrm{Hyd}_{2.3}\left(7.40 \times 10^{-3} \mathrm{~mol} / \mathrm{L} \mathrm{PP}\right.$ and $5.90 \times 10^{-3} \mathrm{~mol} / \mathrm{L}$ TMPT $)$. The adsorption of $\mathrm{Cr}^{6+}$ on selected hydrogels at various $\mathrm{pH}$ values (3.0-8.0) was investigated and represented in Figure $8 \mathrm{~b}$. The adsorption increases with an increase in the $\mathrm{pH}$ value of the medium and a maximum recovery of $\mathrm{Cr}^{6+}$ was obtained in the acidic range, at a $\mathrm{pH}$ value at 5.0. $\mathrm{Cr}^{6+}$ exists in different forms in aqueous solution and the stability of these forms is dependent on the $\mathrm{pH}$ of the solution. In the $\mathrm{pH}$ range of 1 to 6, there are different forms of chromium ions such as $\mathrm{Cr}_{2} \mathrm{O}_{7}{ }^{2-}, \mathrm{HCrO}_{4}{ }^{2-}, \mathrm{Cr}_{3} \mathrm{O}_{10}{ }^{2-}$ and $\mathrm{Cr}_{4} \mathrm{O}_{13}{ }^{2-}$, while $\mathrm{HCrO}_{4}{ }^{2-}$ predominates in the solution [66,67]. Thus $\mathrm{Cr}^{6+}$ ions exist predominantly as $\mathrm{HCrO}_{4}{ }^{2-}$ in an acidic medium and the amino groups $\left(-\mathrm{NH}_{2}\right)$ of acrylamide would be in protonated cationic form $\left(-\mathrm{NH}^{3+}\right)$ to a higher extent in an acidic solution, which causes an electrostatic interaction between the hydrogel and $\mathrm{HCrO}_{4}{ }^{2-}$, resulting in high chromium removal [66,68]. At higher $\mathrm{pH}$ values, the decrease in the adsorption capacity can be associated with the appearance of $\mathrm{Cr}(\mathrm{OH})_{3}$ and anionic $\mathrm{Cr}(\mathrm{OH})^{4-}$ species due to the presence of $\mathrm{OH}^{-}$ions and the uptake decreases. These species may have electrostatic repulsion with the deprotonated amine groups $[69,70]$. So, a $\mathrm{pH}$ of 5 was considered optimum for the removal of $\mathrm{Cr}^{6+}$ and the results were: $128 \mathrm{mg} / \mathrm{g}$ for $\mathrm{Hyd}_{1.3}\left(3.70 \times 10^{-3} \mathrm{~mol} / \mathrm{L} \mathrm{PP}\right.$ and $2.95 \times 10^{-3}$ $\mathrm{mol} / \mathrm{L} \mathrm{TMPT})$ and $102 \mathrm{mg} / \mathrm{g}$ for the $\mathrm{Hyd}_{2.3}\left(7.40 \times 10^{-3} \mathrm{~mol} / \mathrm{L} \mathrm{PP}\right.$ and $\left.5.90 \times 10^{-3} \mathrm{~mol} / \mathrm{L} \mathrm{TMPT}\right)$.

\section{Conclusions}

Poly(acrylamide co-acrylic acid) hydrogels were prepared by free-radical copolymerization of acrylamide (AMD) and acrylic acid (AA) in aqueous solutions, using potassium persulfate (PP) as initiator and trimethylolpropane trimethacrylate (TMPT) as cross-linker, by electron beam irradiation in the dose range of $2.5 \mathrm{kGy}$ to $6 \mathrm{kGy}$. The influence of the absorbed dose and amount of cross-linker on the swelling properties, diffusion coefficient and network parameters of hydrogels was investigated. The gel content increases with the absorbed dose, cross-linking agent (TMPT) and initiator (PP) amount increase. Thus, about $90 \%$ gel content was attained at doses over $5.3 \mathrm{kGy}$. Water uptake increases with the increase of the absorbed dose, up to $4.2 \mathrm{kGy}$. The swelling increases with the increase of TMPT and PP amounts until the point where it becomes constant at the same absorbed dose. The percentage of equilibrium water content (EWC\%) is over $98 \%$ and even higher for hydrogels containing large amounts of TMPT at the same irradiation dose. The best results, meaning the highest swelling, were obtained for a sample irradiated with $4.2 \mathrm{kGy}$. The swelling mostly occurred for $\mathrm{pH}$ values between 3 and 7 . Over a $\mathrm{pH}$ of 7 the change in equilibrium swelling ratio with $\mathrm{pH}$ was slight. It was found that the use of a relatively small amount of TMTP for hydrogel preparation led to an increase in swelling up to $8500 \%$. The water diffusion was non-Fickian and the number average molar mass between cross-links has increased with the absorbed dose and cross-linker content. The variation of the swelling kinetic parameters including the rate constant of first- and second-order swelling $\left(k_{1, S}\right.$ and $\left.k_{2, S}\right)$, the theoretical degree swelling at equilibrium $\left(S_{\max }\right)$ and the initial swelling rate $\left(r_{0}\right)$ with the amount of TMPT, PP and absorbed dose were evaluated. The variation of swelling constant $(k)$, the swelling exponent $(n)$ and the diffusion coefficients $(D)$ with the amount of TMPT and absorbed dose are presented. The swelling exponent (n) slightly increased as a function of absorbed dose (up to $4.2 \mathrm{kGy}$ ) and decreased as the amount of TMPT increased. The diffusion coefficient $(D)$ had the same tendency but increased with the amount of TMPT. The hydrogel network study was done by watching the variation of the number average molar mass between cross-links $\left(\mathrm{M}_{\mathrm{c}} / \mathrm{g}\right.$ mol $\left.\times 10^{-1}\right)$, cross-link density $(\mathrm{q})$, mesh size $(\xi)$ and porosity $(P)$ with the amount of TMPT, PP and absorbed dose. The FTIR spectra of samples irradiated at 2.5 and $6 \mathrm{kGy}$ validate the binding of AMD, AA and TMPT in the structure of the obtained hydrogels. Same sample micrographs present an irregular surface with semi-porous structure and with macro- and micro-pores correlated with the lowest equilibrium water uptake. The hydrogels' efficiency in $\mathrm{Cu}^{2+}$ and $\mathrm{Cr}^{6+}$ removal from aqueous solutions was investigated at room temperature. During the adsorption of metal ions, residual metal ion concentration was measured in solution by 
atomic absorption spectrophotometry. The uptake of $\mathrm{Cu}^{2+}$ gradually increased from $\mathrm{pH} 3.0$ to 4.0 and at $\mathrm{pH} 6.0$ obtained the highest adsorption. $\mathrm{pH} 5$ was considered optimum for removal of $\mathrm{Cr}^{6+}$.

Acknowledgments: The researches were financed by the Romanian program "LAPLAS IV" No. 4N/3.03.2016.

Author Contributions: Elena Manaila performed the experiments, analyzed the data and contributed to the paper writing; Daniel Ighigeanu has conceived and designed the experiments; Gabriela Craciun analyzed the data and wrote the paper; Catalina Cimpeanu, Catalina Barna and Viorel Fugaru performed the heavy metal uptake studies, analyzed data and explained the results.

Conflicts of Interest: The authors declare no conflict of interest.

\section{References}

1. Fernandez-Luqueno, F.; Lopez-Valdez, F.; Gamero-Melo, P.; Suarez, S.L.; Aguilera-Gonzalez, E.N.; Martinez, A.; del Socorro Garcia Guillermo, M.; Hernandez-Martinez, G.; Herrera-Mendoza, R.; Álvarez Garza, M.A.; et al. Heavy metal pollution in drinking water-A global risk for human health: A review. Afr. J. Environ. Sci. Technol. 2013, 7, 567-584.

2. Aragay, G.; Pons, J.; Merkoci, A. Recent trends in macro-, micro- and nanomaterial-based tools and strategies for heavy-metal detection. Chem. Rev. 2011, 111, 3433-3458. [CrossRef] [PubMed]

3. Wan Ngah, W.S.; Hanafiah, M.A.K.M. Removal of heavy metal ions from wastewater by chemically modified plant wastes as adsorbents: A review. Bioresour. Technol. 2008, 99, 3935-3948. [CrossRef] [PubMed]

4. Cheng, S. P. Heavy metal pollution in China: Origin, pattern and control. Environ. Sci. Pollut. Res. 2003, 10, 192-195. [CrossRef]

5. Ip, C.C.M.; Li, X.D.; Zhang, G.; Wong, C.S.C.; Zhang, W.L. Heavy metal and Pb isotopic compositions of aquatic organisms in the Pearl River Estuary, South China. Environ. Pollut. 2005, 138, 494-504. [CrossRef] [PubMed]

6. Peralta-Videa, J.R.; Lopez, M.L.; Narayan, M.; Saupe, G.; Gardea-Torresdey, J. The biochemistry of environmental heavy metal uptake by plants: Implications for the food chain. Int. J. Biochem. Cell Biol. 2009, 41, 1665-1677. [CrossRef] [PubMed]

7. Yang, S.P.; Fu, S.Y.; Liu, H.; Zhou, Y.M.; Li, X.Y. Hydrogel Beads Based on Carboxymethyl Cellulose for Removal Heavy Metal Ions. J. Appl. Polym. Sci. 2011, 119, 1204-1210. [CrossRef]

8. Meunier, N.; Drogui, P.; Montane, C.; Hausler, R.; Mercier, G.; Blais, J.F. Comparison between electrocoagulation and chemical precipitation for metals removal from acidic soil leachate. J. Hazard. Mater. 2006, 137, 581-590. [CrossRef] [PubMed]

9. Charerntanyarak, L. Heavy metals removal by chemical coagulation and precipitation. Water Sci. Technol. 1999, 39, 135-138. [CrossRef]

10. Bessbousse, H.; Rhlalou, T.; Verchere, J.F.; Lebrun, L. Removal of heavy metal ions from aqueous solutions by filtration with a novel complexing membrane containing poly(ethyleneimine) in a poly(vinyl alcohol) matrix. J. Membr. Sci. 2008, 307, 249-259. [CrossRef]

11. Vijayalakshmi, A.; Arockiasam, D.L.; Nagendran, A.; Mohan, D. Separation of proteins and toxic heavy metal ions from aqueous solution by CA/PC blend ultrafiltration membranes. Sep. Purif. Technol. 2008, 62, 32-38. [CrossRef]

12. Alyuz, B.; Veli, S. Kinetics and equilibrium studies for the removal of nickel and zinc from aqueous solutions by ion exchange resins. J. Hazard. Mater. 2009, 167, 482-488. [CrossRef] [PubMed]

13. Dabrowski, A.; Hubicki, Z.; Podko'scielny, P.; Robens, E. Selective removal of the heavy metal ions from waters and industrial wastewaters by ion-exchange method. Chemosphere 2004, 56, 91-106. [CrossRef] [PubMed]

14. Basha, C.A.; Somasundaram, M.; Kannadasan, T.; Lee, C.W. Heavy metals removal from copper smelting effluent using electrochemical filter press cells. Chem. Eng. J. 2011, 171, 563-571. [CrossRef]

15. Chen, Q.; Zhu, L.; Zhao, C.; Zheng, J. Hydrogels for Removal of Heavy Metals from Aqueous Solution. J. Environ. Anal. Toxicol. 2012. [CrossRef]

16. Sprynskyy, M. Solid-liquid-solid extraction of heavy metals $(\mathrm{Cr}, \mathrm{Cu}, \mathrm{Cd}, \mathrm{Ni}$ and $\mathrm{Pb})$ in aqueous systems of zeolite-sewage sludge. J. Hazard. Mater. 2009, 161, 1377-1383. [CrossRef] [PubMed] 
17. Eloussaief, M.; Kallel, N.; Yaacoubi, A.; Benzina, M. Mineralogical identification, spectroscopic characterization and potential environmental use of natural clay materials on chromate removal from aqueous solutions. Chem. Eng. J. 2011, 168, 1024-1031. [CrossRef]

18. Erdem, E.; Karapinar, N.; Donat, R. The removal of heavy metal cations by natural zeolites. J. Coll. Interface Sci. 2004, 280, 309-314. [CrossRef] [PubMed]

19. Eloussaief, M.; Benzina, M. Efficiency of natural and acid-activated calys in the removal of $\mathrm{Pb}$ (II) from aqueous solutions. J. Hazard. Mater. 2010, 178, 753-757. [CrossRef] [PubMed]

20. Eloussaief, M.; Sdiri, A.; Benzina, M. Modelling the adsorption of mercury onto natural and aluminium pillared clays. Environ. Sci. Pollut. Res. 2013, 20, 469-479. [CrossRef] [PubMed]

21. Barakat, M.A. New trends in removing heavy metals from industrial wastewater. Arabian J. Chem. 2011, 4, 361-377. [CrossRef]

22. Peng, X.W.; Zhong, L.X.; Ren, J.L.; Sun, R.C. Highly effective adsorption of heavy metal ions from aqueous solutions by macroporous xylan-rich hemicelluloses-based hydrogel. J. Agric. Food Chem. 2012, 60, 3909-3916. [CrossRef] [PubMed]

23. Zheng, Y.; Wang, A. Evaluation of ammonium removal using a chitosan-gpoly(acrylic acid)/rectorite hydrogel composite. J. Hazard. Mater. 2009, 171, 671-677. [CrossRef] [PubMed]

24. Yetimoglu, E.K.; Kahraman, M.V.; Ercan, O.; Akdemir, Z.S.; Apohan, N.K. N-vinylpyrrolidone/acrylic acid/2-acrylamido-2-methylpropane sulfonic acid based hydrogels: Synthesis, characterization and their application in the removal of heavy metals. React. Funct. Polym. 2007, 67, 451-460. [CrossRef]

25. Gulrez, K.H.S.; Al-Assaf, S.; Phillips, O.G. Chapter 5: Hydrogels: Methods of Preparation, Characterisation and Applications. In Progress in Molecular and Environmental Bioengineering —From Analysis and Modeling to Technology Applications; Capri, A., Ed.; InTech: Rijeka, Croatia, 2011; pp. 117-150.

26. Hennink, W.E. van Nostrum, C.F. Novel crosslinking methods to design hydrogels. Adv. Drug. Deliver. Rev. 2002, 54, 13-36. [CrossRef]

27. Barbucci, R.; Leone, G.; Vecchiullo, A. Novel carboxymethylcellulose-based microporous hydrogels suitable for drug delivery. J. Biomat. Sci. Polym. E 2004, 15, 607-619. [CrossRef]

28. Said, H.M.; Abd Alla, S.G.A.; El-Naggar, A.W.M. Synthesis and characterization of novel gels based on carboxymethyl cellulose/acrylic acid prepared by electron beam irradiation. React. Funct. Polym. 2004, 61, 397-404. [CrossRef]

29. Fei, B.; Wach, R.A.; Mitomo, H.; Yoshii, F.; Kume, T. Hydrogel of biodegradable cellulose derivatives. I. Radiation-induced crosslinking of CMC. J. Appl. Polym. Sci. 2000, 78, 278-283. [CrossRef]

30. Liu, P.F.; Zhai, M.L.; Li, J.Q.; Peng, J.; Wu, J.L. Radiation preparation and swelling behavior of sodium carboxymethyl cellulose hydrogels. Radiat. Phys. Chem. 2002, 63, 525-528. [CrossRef]

31. Wang, M.; Xu, L.; Ju, X.; Peng, J.; Zhai, M.L.; Li, J.Q.; Wei, G.S. Enhanced radiation crosslinking of carboxymethylated chitosan in the presence of acids or polyfunctional monomers. Polym. Degrad. Stabil. 2008, 93, 1807-1813. [CrossRef]

32. Ismail, O.; Kipcak, A.S.; Piskin, P. Modeling of absorption kinetics of poly(acrylamide) hydrogels crosslinked by EGDMA and PEGDMAs. Res. Chem. Intermediat. 2013, 39, 907-919. [CrossRef]

33. Hassan, S.; Yasin, T. Synthesis of radiation crosslinked poly(acrylic acid) in the presence of phenyltriethoxysilane. Radiat. Phys. Chem. 2014, 97, 292-297. [CrossRef]

34. Karadag, E.; Saraydin, D. Swelling studies of super water retainer acrylamide/crotonic acid hydrogels crosslinked by trimethylolpropane triacrylate and 1,4-butanediol dimethacrylate. Polym. Bull. 2002, 48, 299-307. [CrossRef]

35. Craciun, G.; Manaila, E.; Stelescu, M.D. Electron Beam Synthesis and Characterization of Acrylamide/Acrylic Acid Hydrogels Using Trimethylolpropane Trimethacrylate as Cross-Linker. J. Chem. 2016, 2016, 1470965. [CrossRef]

36. Fiti, M. Ionizing Radiation Chemical Dosimetry. In Dozimetria Chimica a Radiatiilor Ionizante; Editura Academiei Republicii Socialiste Romania: Bucuresti, Romania, 1973; pp. 24-70.

37. Cleland, M.R. Industrial Applications of Electron Accelerators-Ion Beam Applications. In Proceedings of the CERN Accelerator School/Small Accelerator Course, Zeegse, The Netherlands, 24 May-2 June 2005.

38. Marandi, G.B.; Mahdavinia, G.R.; Ghafary, S. Collagen-g-poly(Sodium Acrylate-co-Acrylamide)/sodium montmorillonite superabsorbent nanocomposites: Synthesis and swelling behavior. J. Polym. Res. 2011, 18, 1487-1499. [CrossRef] 
39. Karadag, E.; Saraydin, D.; Sahiner, N.; Güven, O. Radiation induced acrylamide/citric acid hydrogelas and their swelling behaviors. J. Macromol. Sci. Part A 2001, 38, 1105-1121. [CrossRef]

40. Pourjavadi, A.; Kurdtabar, M. Collagen-based highly porous hydrogel without any porogen: Synthesis and characteristics. Eur. Polym. J. 2007, 43, 877-889. [CrossRef]

41. Davidovich-Pinhas, M.; Bianco-Peled, H. A quantitative analysis of alginate swelling. Carbohydr. Polym. 2010, 79, 1020-1027. [CrossRef]

42. Karadag, E.; Uzum, O.B.; Saraydin, D. Swelling equilibria and dye adsorption studies of chemically crosslinked superabsorbent acrylamide/maleic acid hydrogels. Eur. Polym. J. 2002, 38, 2133-2141. [CrossRef]

43. Jabbari, E.; Nozari, S. Swelling behaviour of acrylic acid hydrogels prepared by c-radiation crosslinking of polyacrylic acid in aqueous solution. Eur. Polym. J. 2000, 36, 2685-2692. [CrossRef]

44. Ostrowska-Czubenko, J.; Gierszewska-Drużyńska, M. Mechanism of water diffusion into noncrosslinked and ionically crosslinked chitosan membranes. In Progress on Chemistry and Application of Chitin and its Derivatives; Jaworska, M.M., Ed.; Polish Chitin Society: Łódź, Poland, 2012; Volume 17, pp. 59-66.

45. Khare, A.R.; Peppas, N.A. Swelling/deswelling of anionic copolymer gels. Biomaterials 1995, 16, 559-567. [CrossRef]

46. Lin, W.C.; Yu, D.G.; Yang, M.C. pH-sensitive polyelectrolyte complex gel microspheres composed of chitosan/sodium tripolyphosphate/dextran sulfate: Swelling kinetics and drug delivery properties. Coll. Surf. B 2005, 44, 143-151. [CrossRef] [PubMed]

47. Rao, K.V.R.; Devi, K.P.; Buri, P. Cellulose matrices for zero-order release of soluble drugs. Drug Dev. Ind. Pharm. 1988, 14, 2299-2320.

48. Munday, D.L.; Cox, P.J. Compressed xanthan and karaya gum matrices: Hydration, erosion and drug release mechanisms. Int. J. Pharm. 2000, 203, 179-192. [CrossRef]

49. Hill, D.J.T.; Lim, M.C.H.; Whittaker, A.K. Water diffusion in hydroxyethyl methacrylate (HEMA)-based hydrogels formed by $\gamma$-radiolysis. Polym. Int. 1999, 48, 1046-1052. [CrossRef]

50. Krongauz, V.V. Diffusion in polymers dependence on crosslink density. J. Therm. Anal. Calor. 2010, 102, 435-445. [CrossRef]

51. Demeter, M.; Virgolici, M.; Vancea, C.; Scarisoreanu, A.; Kaya, M.G.A.; Meltzer, V. Network structure studies on gamma-irradiated collagen-PVP superabsorbent hydrogels. Radiat. Phys. Chem. 2017, 131, 51-59. [CrossRef]

52. Yiamsawas, D.; Kangwansupamonkon, W.; Chailapakul, O.; Kiatkamjornwong, S. Synthesis and swelling properties of poly[acrylamide-co-(crotonic acid)] superabsorbents. React. Funct. Polym. 2007, 67, 865-882. [CrossRef]

53. Ding, Z.Y.; Aklonis, J.J.; Salovey, R. Model filled polymers. VI. Determination of the crosslink density of polymeric beads by swelling. J. Polym. Sci. B 1991, 29, 1035-1038. [CrossRef]

54. Karadag, E.; Saraydin, D.; Güven, O. Influence of some crosslinkers on the swelling of acrylamide-crotonic acid hydrogels. Turk. J. Chem. 1997, 21, 151-161.

55. Thakur, A.; Wanchoo, R.K.; Singh, P. Structural Parameters and Swelling Behavior of pH Sensitive Poly(acrylamide-co-acrylic acid) Hydrogels. Chem. Biochem. Eng. Q 2011, 25, 181-194.

56. Nesrinne, S.; Djamel, A. Synthesis, characterization and rheological behavior of $\mathrm{pH}$ sensitive poly(acrylamide-co-acrylic acid) hydrogels. Arabian J. Chem. 2017, 10, 539-547. [CrossRef]

57. Murugan, R.; Mohan, S.; Bigotto, A. FTIR and Polarized Raman Spectra of Acrylamide and Polyacrylamide. J. Korean Phys. Soc. 1998, 32, 505-512.

58. Geethanjali, R.; Sabirneeza, A.A.F.; Subhashini, S. Water-Soluble and Biodegradable Pectin-Grafted Polyacrylamide and Pectin-Grafted Polyacrylic Acid: Electrochemical Investigation of Corrosion-Inhibition Behaviour on Mild Steel in 3.5\% NaCl Media. Indian J. Mater. Sci. 2014, 2014, 356075.

59. Li, Y.H.; Chen, X.L.; Liu, Y.M.; Lu, J.Q.; Zhao, Y.S. Synthesis and characterization of poly(aspartic acid) composite hydrogels with inorganic MCM-41 cross-linker. Iran. Polym. J. 2014, 23, 907-916. [CrossRef]

60. Xie, Y.T.; Wang, A.Q. Preparation and Swelling Behaviourof Chitosan-g-poly(acrylic acid)/Muscovite Superabsorbent Composites. Iran. Polym. J. 2010, 19, 131-141.

61. Wu, Y.X.; Zhou, J.H.; Ye, C.C.; Sun, H.S.; Zhao, R.J. Optimized Synthesis of Lignosulphonate-g-poly(acrylic acid-co-acrylamide) Superabsorbent Hydrogel Based on the Taguchi Method. Iran. Polym. J. 2010, 19, 511-520. 
62. Kong, W.Q.; Ren, J.L.; Wang, S.Y.; Chen, Q.F. Removal of heavy metals from aqueous solutions using acrylic-Modified sugarcane bagasse-Based adsorbents: Equilibrium and kinetic studies. Bioresources 2014, 9, 3184-3196. [CrossRef]

63. Ibrahim, A.G.; Hai, F.A.; Wahab, H.A.; Mahmoud, H. Synthesis, Characterization, Swelling Studies and Dye Removal of Chemically Crosslinked Acrylic Acid/Acrylamide/N, N-Dimethyl Acrylamide Hydrogels. Am. J. Appl. Chem. 2016, 4, 221-234. [CrossRef]

64. Li, W.; Zhao, H.; Teasdale, P.R.; John, R.; Zhang, S. Synthesis and characterisation of a polyacrylamide-polyacrylic acid copolymer hydrogel for environmental analysis of $\mathrm{Cu}$ and $\mathrm{Cd}$. React. Funct. Polym. 2002, 52, 31-41. [CrossRef]

65. Atia, A.A.; Donia, A.M.; Hussin, R.A.; Rashad, R.T. Swelling and metal ion uptake characteristics of kaolinite containing poly [(acrylic acid)-co-acrylamide] hydrogels. Desalination Water Treat. 2009, 3, 73-82. [CrossRef]

66. Shouman, M.A.; Fathy, N.A.; Khedr, S.A.; Attia, A.A. Comparative Biosorption Studies of Hexavalent Chromium Ion onto Raw and Modified Palm Branches. Adv. Phys. Chem. 2013, 2013, 159712. [CrossRef]

67. Malkoc, E.; Nuhoglu, Y. Fixed bed studies for the sorption of chromium(VI) onto tea factory waste. Chem. Eng. Sci. 2006, 61, 4363-4372. [CrossRef]

68. Dambies, L.; Guimon, C.; Yiacoumi, S.; Guibal, E. Characterization of metal ion interactions with chitosan by X-ray photoelectron spectroscopy. Coll. Surf. A 2001, 77, 203-214. [CrossRef]

69. Rashid, J.; Barakat, M.A.; Alghamdi, M.A. Adsorption of Chromium (VI) from Wastewater by Anion Exchange Resin. J. Adv. Catal. Sci. Technol. 2014, 1, 26-34.

70. Kumar, P.A.; Chakraborty, S.; Ray, M. Removal and recovery of chromium from wastewater using short chain polyaniline synthesized on jute fiber. Chem. Eng. J. 2008, 141, 130-140. [CrossRef]

(C) 2017 by the authors. Licensee MDPI, Basel, Switzerland. This article is an open access article distributed under the terms and conditions of the Creative Commons Attribution (CC BY) license (http://creativecommons.org/licenses/by/4.0/). 